\title{
Role of the diamagnetic zinc(II) ion in determining the electronic structure of lanthanide single-ion magnets
}

\author{
Apoorva Upadhyay, ${ }^{[a]}$ Chinmoy Das, ${ }^{[a]}$ Shefali Vaidya, ${ }^{[a]}$ Saurabh Kumar Singh, ${ }^{[a]}$ Tulika Gupta, ${ }^{[a]}$ Ranajit \\ Mondol, ${ }^{[a]}$ Stuart K Langley, ${ }^{[b]}$ Keith S Murray, ${ }^{[c]}$ Gopalan Rajaraman*, ${ }^{[a]}$ and Maheswaran \\ Shanmugam*[a]
}

Dedication ((optional))

\begin{abstract}
Four complexes containing $\operatorname{Dy}(\mathrm{III})$ and $\operatorname{Pr}(\mathrm{III})$ ions and their $\operatorname{Ln}(\mathrm{III})-\mathrm{Zn}(\mathrm{II})$ analogs have been synthesized in order to study the influence that a diamagnetic $\mathrm{Zn}(\mathrm{II})$ ion has on the electronic structure and hence, the magnetic properties of the Dy(III) and $\operatorname{Pr}(\mathrm{III})$ single ions. Single crystal $\mathrm{X}$-ray diffraction revealed the molecular structures as $\left[\mathrm{Dy}{ }^{\prime \prime \prime}(\mathrm{HL})_{2}\left(\mathrm{NO}_{3}\right)_{3}\right] \quad(\mathbf{1}), \quad\left[\mathrm{Pr}{ }^{\prime \prime \prime}(\mathrm{HL})_{2}\left(\mathrm{NO}_{3}\right)_{3}\right] \quad$ (2), $\left[\mathrm{ZnDy}(\mathrm{L})_{2}\left(\mathrm{NO}_{3}\right)_{2}\left(\mathrm{CH}_{3} \mathrm{COO}\right)\right](3)$ and $\left[\mathrm{Zn} 2 \operatorname{Pr}(\mathrm{L})_{2}\left(\mathrm{CH}_{3} \mathrm{COO}\right)_{4}\left(\mathrm{NO}_{3}\right)\right]$ (4) (where $\mathrm{HL}=2-$-methoxy-6-[(E)-phenyliminomethyl]phenol). Dc and ac magnetic data were collected for all the four complexes. Compounds 1 and 3 display frequency dependent out-of-phase susceptibility signals $\left(\chi_{M}{ }^{\prime \prime}\right)$ which is a characteristic signature for a single-molecule magnet (SMM). Although $\mathbf{1}$ and $\mathbf{3}$ are chemically similar, a fivefold increase in the anisotropic barrier $\left(U_{\text {eff }}\right)$ is observed for $3\left(83 \mathrm{~cm}^{-1}\right)$, compared to $1\left(16 \mathrm{~cm}^{-1}\right)$. To infer the role of the dipolar interaction in the magnetization relaxation dynamics of $\mathbf{3}$, ac measurements were performed in solution. The anisotropic barrier was found to increase by $8 \mathrm{~cm}^{-1}\left(89.2 \mathrm{~cm}^{-1}, \tau_{0}=1.0447 \times 10^{-11} \mathrm{~s}\right)$ compared to the solid state sample. To rationalize the larger anisotropic barrier ( 1 vs 3 ), detailed $a b$ initio calculations were performed. The calculations yielded $g$ tensors of the Kramers ground doublet of $g_{z z}=19.443$ for $\mathbf{1 a}$ and $g_{z z}$ $=19.092$ for $\mathbf{1 b}$ (two unique ions in the asymmetric unit of $\mathbf{1}$ ), while the $g$ tensors for 3 are found to be $g_{z z}=18.82$. The computed magnetic susceptibility profile using the extracted parameters is in excellent agreement with the experimental magnetic data confirming the reliability of the calculated parameters. Although the ground state Kramer's doublet in both $\mathbf{1}$ and $\mathbf{3}$ are axial in nature, a significant difference in the energy gap $\left(U_{\text {eff }}\right)$ between the ground and first excited Kramer's doublet is calculated. This energy gap is governed by the electrostatic repulsion between the Dy(III) ion and the
\end{abstract}

[a] A. Upadhyay, C. Das, S. Vaidya, R. Mondol, S. K. Singh, T. Gupta, Prof. G. Rajaraman, Prof. M. Shanmugam

Department of Chemistry

Indian Institute of Technology Bombay

Powai, Mumbai, Maharashtra, India-400076.

E-mail: rajaraman@chem.iitb.ac.in (GR); eswar@chem.iitb.ac.in (MS)

[b] Dr. S. K. Langley

School of Science and the Environment

Division of Chemistry

Manchester Metropolitan University

Manchester M15 6BH, United Kingdom.

[c] Prof. K. S. Murray

Department of Chemistry

Monash University

Victoria-3800. Clayton, Australia.

Electronic Supplementary Information (ESI) available: CCDC

numbers: $916656,990256-990257,1471848$. See DOI: $10.1039 / \mathrm{b} 000000 \mathrm{x} /$ additional charge density found for the phenoxo bridging ligand in $\mathbf{3}$ This extra charge density was found to be a consequence of the presence of the diamagnetic $\mathrm{Zn}(\mathrm{II})$ ion present in the complex. To explore the influence of diamagnetic ions on the magnetic properties further, previously reported and structurally related $\mathrm{Zn}-\mathrm{Dy}(\mathrm{III})$ complexes were analysed. These structurally analogous complexes unambiguously suggest that the electrostatic repulsion is found to be maximal when the $\mathrm{Zn}-\mathrm{O}-\mathrm{Dy}-\mathrm{O}$ dihedral angle is small, which is an ideal condition to maximize the anisotropic barrier in Dy(III) complexes. Thus employing a diamagnetic $\mathrm{Zn}(\mathrm{II})$ ion near the coordination sphere of a $\operatorname{Ln}($ III) ion, the charge density on the bridging ligand can be manipulated, significantly improving the SMM properties.

\section{Introduction}

The presence of unquenched orbital angular momentum for the majority of trivalent lanthanide ions makes these attractive candidates towards developing new molecular magnetic materials. ${ }^{[1]}$ Exploiting the large intrinsic orbital angular momentum of $\mathrm{Ln}^{3+}$ ions allowed for the observation in 2003 of slow relaxation of the magnetization in a $\mathrm{Tb}$ (III) bispthalocyanin sandwich complex - the first lanthanide complex to display such behaviour. ${ }^{[2]}$ This property, which is purely of molecular origin led to the term single-molecule magnet (SMM). If the property originates from a single metal ion, then the term single-ion magnet (SIM) is preferably used. SMMs or SIMS offer a host of potential applications such as high density data storage, as molecular qubits and as components in spintronic devices. ${ }^{[3]}$ In addition other novel magnetic phenomenon such as singlemolecule toroidal behavior has been detailed. ${ }^{[4]}$ Numerous lanthanide based coordination complexes have subsequently flooded the literature, ${ }^{[5]}$ with examples revealing record high anisotropy barriers $\left(U_{\text {eff }}\right)$, the energy required to flip the orientation of the magnetization vector, with values as large as $1261 \mathrm{~cm}^{-1}{ }^{6}{ }^{6]}$ Although the magnitude of the anisotropy barrier is significantly larger than the average thermal energy at room temperature, in many SMM complexes the blocking temperature $\left(T_{B}\right)$, given as a magnetization relaxation time of $100 \mathrm{~s}$, lies at extremely low temperatures, usually $<2 \mathrm{~K}$, due to quantum tunneling of the magnetization (QTM). At the present time there is no straight forward route towards tackling the problem of this quantum behavior, however, one method of subduing QTM can be achieved by enhancing the exchange interaction between lanthanide ions. This was elegantly shown by Long and coworkers in radical bridged dinuclear lanthanide complexes. ${ }^{[7]}$ Upon arresting the fast QTM, significant gains in the blocking temperature was observed, $T_{B}=14 \mathrm{~K}$ for a $\mathrm{N}_{2}{ }^{3-}$ radical bridged $\mathrm{Tb}^{\mathrm{III}}{ }_{2}$ complex. ${ }^{[5 \mathrm{a}]}$ Enhancing the magnetic exchange interaction 
of $\operatorname{Ln}(\mathrm{III})$ ions can also be achieved using transition metal ions. Complexes such as $\left\{\mathrm{Cr}^{\prime \prime \prime}{ }_{2} \mathrm{Dy}{ }^{\prime \prime \prime}{ }_{2}\right\}$ and $\left\{\mathrm{Ni}_{2}{ }_{2} \mathrm{Dy}{ }^{\prime \prime \prime}{ }_{2}\right\}$, reported by us, have shown a significant reduction in QTM due to the nonnegligible magnetic exchange interactions between Dy"lI and transition metal ions.$^{[8]}$ Although the above mentioned statement holds true, a suitable ligand field around the lanthanide ions plays a substantial role in opening or arresting the under barrier relaxation (QTM) mechanism..$^{[9]}$ Undeniably a combination of strong magnetic exchange along with a suitable ligand field around the lanthanide ion(s) will drastically enhance the blocking temperature of lanthanide complexes.

It has been shown that the orientation of the $g_{z z}$ axis in anisotropic lanthanide ion complexes is governed by the electrostatic charges of the ligands rather than the geometry. ${ }^{[1 \mathrm{~b}}$, 9-10] An appropriate ligand design and coordination environment, based on the nature of the ion is therefore required. For example, for a $4 \mathrm{f}$ ion with a prolate electron density distribution, an equatorial ligand field is preferred; whereas if an oblate ion is used an axial ligand field is preferred. These conditions are necessary to stabilize the Ising magnetic anisotropy in those complexes. ${ }^{[9]}$ Such an approach appears to be a promising route for stabilizing SMMs, with a mononuclear dysprosium complex revealing magnetic hysteresis up at $30 \mathrm{~K}$ (sweep rate $20 \mathrm{mT} / \mathrm{s}$ ) using this strategy. ${ }^{[5 a]}$

It is not a trivial exercise to control the exchange interaction between $3 d$ and $4 f$ ions with the majority of $3 d-4 f$ metal complexes, exhibiting weak exchange interactions, leading to fast magnetic relaxation. Due to these observations our focus has shifted towards modifying and controlling the electrostatic charge of the ligand field which governs the orientation of the $g_{z z}$ axis, as this may be easier to modify and optimize for a particular system. In this article we develop a means to modulate the electrostatic charge around the trivalent $L n$ ion by incorporating the diamagnetic $\mathrm{Zn}$ (II) ion into various complexes. ${ }^{[11]}$ We report the factors which influence the magnetization relaxation dynamics in four complexes of molecular formulae $\left[\mathrm{Ln}^{\prime \prime \prime}(\mathrm{HL})_{2}\left(\mathrm{NO}_{3}\right)_{3}\right]$ where $\mathrm{Ln}(\mathrm{III})=\mathrm{Dy}(\mathbf{1})$ or $\mathrm{Pr}$ (2), $\left[\mathrm{Zn}^{\prime \prime} \mathrm{Dy} \mathrm{y}^{\prime \prime \prime}(\mathrm{L})_{2}\left(\mathrm{CH}_{3} \mathrm{CO}_{2}\right)\left(\mathrm{NO}_{3}\right)_{2}\right]$

(3) and $\left[\mathrm{Zn}_{2}{ }_{2} \mathrm{Pr}^{\prime \prime \prime}(\mathrm{L})_{2}\left(\mathrm{CH}_{3} \mathrm{CO}_{2}\right)_{4} \mathrm{NO}_{3}\right]$ (4), where $\mathrm{HL}=2$-methoxy-6-[(E) phenyliminomethyl]phenol.

\section{Results and Discussion}

In order to probe the effect of incorporating a diamagnetic ion such as $\mathrm{Zn}(\mathrm{II})$ on the electronic structure and therefore the magnetic properties of lanthanide based single ion magnets (SIMs), we have synthesized a series of homometallic and heterometallic complexes. The reaction of the neutral Schiff base ligand 2-methoxy-6-[(E)-phenyliminomethyl] phenol (HL) with $\mathrm{Ln}\left(\mathrm{NO}_{3}\right)_{3} \cdot \mathrm{xH}_{2} \mathrm{O}$ (where $\mathrm{Ln}=\mathrm{Dy}$ or $\mathrm{Pr}$ ) in ethanol or methanol yielded orange crystals which were suitable for $\mathrm{x}$-ray diffraction study (Scheme 1).

\section{Structural Description}

Single crystal $\mathrm{X}$-ray diffraction studies revealed the molecular formula as $\left[\mathrm{Dy}(\mathrm{HL})_{2}\left(\mathrm{NO}_{3}\right)_{3}\right](1)$ and $\left[\mathrm{Pr}(\mathrm{HL})_{2}\left(\mathrm{NO}_{3}\right)_{3}\right]$ (2) following the top reaction in scheme 1 . Using the deprotonated ligand $(\mathrm{L})$ and $\mathrm{Dy}\left(\mathrm{NO}_{3}\right)_{3} \cdot \mathrm{xH}_{2} \mathrm{O}$ in the presence of zinc acetate we obtained $\left[\mathrm{ZnDy}(\mathrm{L})_{2}\left(\mathrm{NO}_{3}\right)_{2}\left(\mathrm{CH}_{3} \mathrm{COO}\right)\right]$ (3) (see middle panel in scheme 1) when $\operatorname{Pr}\left(\mathrm{NO}_{3}\right)_{3} \cdot \mathrm{xH}_{2} \mathrm{O}$ was used we obtained $\left[\mathrm{Zn}_{2} \operatorname{Pr}(\mathrm{L})_{2}\left(\mathrm{NO}_{3}\right)\left(\mathrm{CH}_{3} \mathrm{COO}\right)_{4}\right]$ (4) (scheme 1, bottom panel).

Scheme 1. General synthetic method followed for the isolation of complexes 1-4

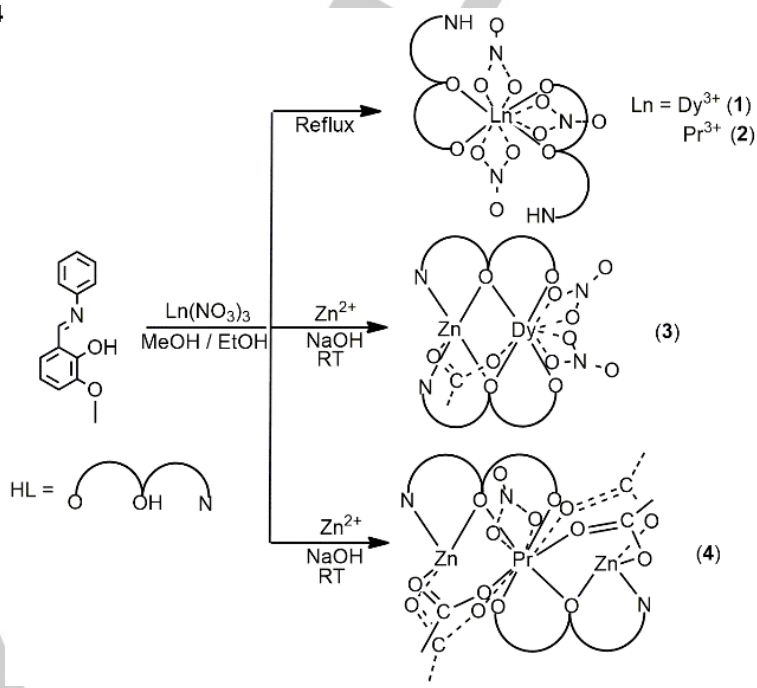

The crystal structures of all four complexes are shown in Figure 1. Complexes $\mathbf{1}$ and $\mathbf{2}$ crystallize in the orthorhombic space groups, Aba2 and Pbca, respectively. Complexes 3 and 4 crystallize in triclinic $(P-1)$ and monoclinic $(C 2 / c)$ crystal systems (Table 1).

Table 1. Crystallographic parameters for the complexes 1 - 4 .

\begin{tabular}{|c|c|c|c|c|}
\hline 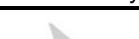 & 1 & 2 & 3 & 4 \\
\hline $\begin{array}{l}\text { Formula } \\
\text { Size }\end{array}$ & $\begin{array}{c}\mathrm{Dy}_{1} \mathrm{C}_{28} \mathrm{H}_{26} \\
\mathrm{~N}_{5} \mathrm{O}_{13} \\
0.2 \times 0.2 \times \\
0.2\end{array}$ & $\begin{array}{c}\mathrm{Pr}_{1} \mathrm{C}_{28} \mathrm{H}_{26} \mathrm{~N}_{5} \mathrm{O} \\
{ }_{13} \\
0.2 \times 0.15 \times \\
0.15\end{array}$ & $\begin{array}{c}\mathrm{Zn}_{1} \mathrm{Dy}_{1} \mathrm{C}_{32} \mathrm{H} \\
27 \mathrm{~N}_{4} \mathrm{O}_{14} \\
0.41 \times 0.21 \\
\times 0.07\end{array}$ & $\begin{array}{c}\mathrm{Zn}_{2} \mathrm{Pr}_{1} \mathrm{C}_{38} \mathrm{H} \\
41 \mathrm{~N}_{3} \mathrm{O}_{16} \mathrm{Cl}_{4} \\
0.13 \times 0.11 \\
\times 0.07\end{array}$ \\
\hline System & $\begin{array}{l}\text { Orthorhom } \\
\text { bic }\end{array}$ & Orthorhombic & Triclinic & Monoclinic \\
\hline $\begin{array}{l}\text { Space } \\
\text { group }\end{array}$ & Aba2 & Pbca & $P-1$ & $C 2 / c$ \\
\hline$a[\AA]]$ & $17.65(3)$ & $9.77(6)$ & $11.13(5)$ & $15.58(5)$ \\
\hline$b[\AA]$ & $54.09(9)$ & $17.24(10)$ & $12.52(6)$ & $15.79(5)$ \\
\hline$c[\AA]$ & $9.55(16)$ & $36.28(2)$ & $13.22(6)$ & $18.94(6)$ \\
\hline$\alpha\left[^{\circ}\right]$ & 90 & 90 & $105.88(10)$ & 90 \\
\hline$\beta\left[^{\circ}\right]$ & 90 & 90 & $91.75(5)$ & $97.84(4)$ \\
\hline$\gamma\left[^{\circ}\right]$ & 90 & 90 & $94.46(6)$ & 90 \\
\hline $\mathrm{V}\left[\AA^{3}\right]$ & $9120(3)$ & $6111.5(6)$ & $1764.3(14)$ & $4620(3)$ \\
\hline Z & 12 & 8 & 2 & 4 \\
\hline$P_{\text {cald }}\left(\mathrm{gcm}^{-1}\right)$ & 1.755 & 1.699 & 1.731 & 1.731 \\
\hline $2 \theta\left[^{\circ}\right]$ & 58.34 & 53.46 & 58.34 & 50 \\
\hline Radiation & $\mathrm{MoK}_{\alpha}$ & $\mathrm{MoK}_{a}$ & $\mathrm{MoK}_{a}$ & $\mathrm{MoK}_{a}$ \\
\hline$\lambda[\AA ̊]$ & 0.71073 & 0.71073 & 0.71073 & 0.71073 \\
\hline $\mathrm{T}(\mathrm{K})$ & 100 & 100 & 100 & 100 \\
\hline Reflns & 33334 & 95002 & 29756 & 17051 \\
\hline Ind. Reflns & 11627 & 6481 & 9054 & 4062 \\
\hline $\begin{array}{l}\text { Reflns with } \\
>2 \sigma(I)\end{array}$ & 9529 & 5346 & 8566 & 3704 \\
\hline $\mathrm{R} 1$ & 0.0494 & 0.0308 & 0.0348 & 0.0630 \\
\hline wR2 & 0.1015 & 0.0639 & 0.0910 & 0.1650 \\
\hline
\end{tabular}


The homometallic complexes 1 and 2, reveal that the lanthanide ion is 10-coordinate, with a bicapped distorted square anti-prism geometry (Figures 1D-1F). The geometries were confirmed by Continuous Shape Measurement (CShM) software. ${ }^{[12]}$ The three chelating nitrate ions in $\mathbf{1}$ and $\mathbf{2}$ account for six out of the ten coordination sites, neutralizing the trivalent cationic charge on the lanthanide ion. The remaining four coordination sites are completed by the two neutral Schiff base ligands, however, the proton bound to the phenolic oxygen of the free ligands has migrated to the imine nitrogen atom upon coordination with the lanthanide ion. ${ }^{[13]}$
A)

D)
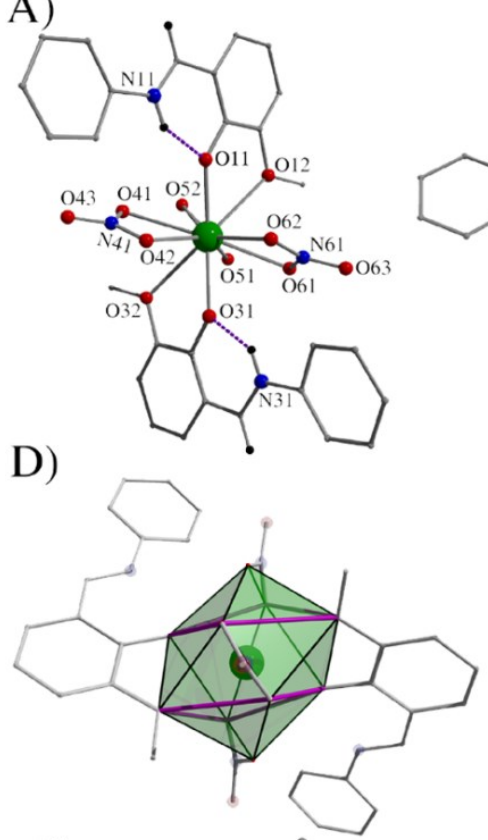

G)

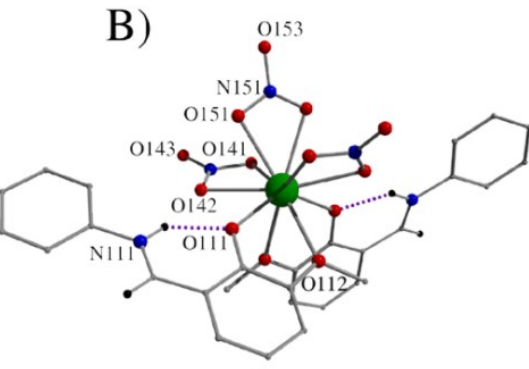

E)
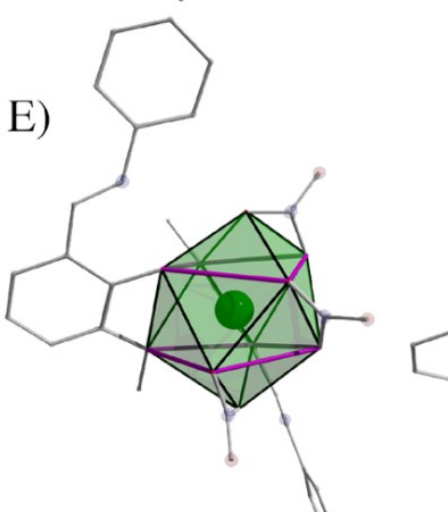

C)

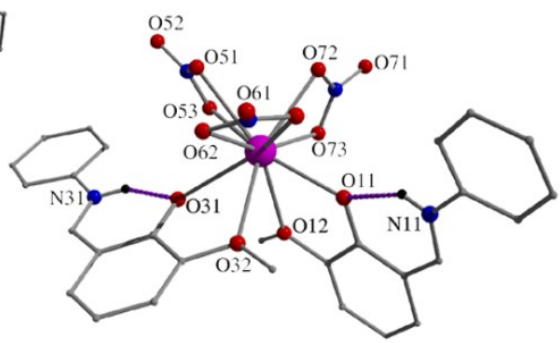

F)
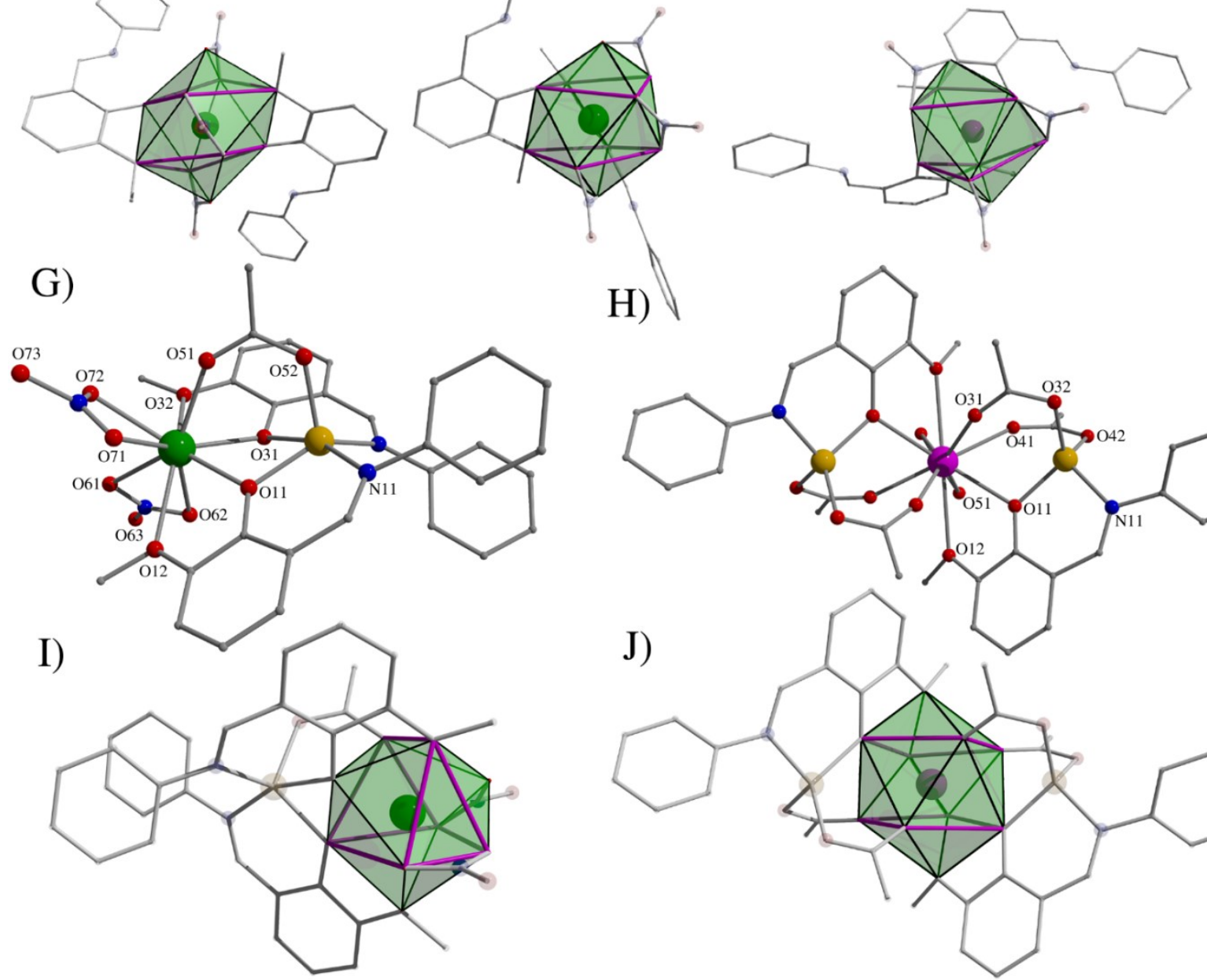

$\mathrm{H})$<smiles>C1CCCCC1</smiles>

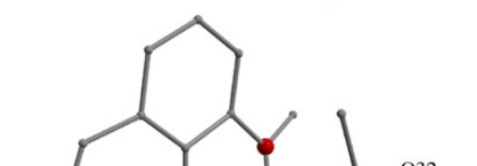

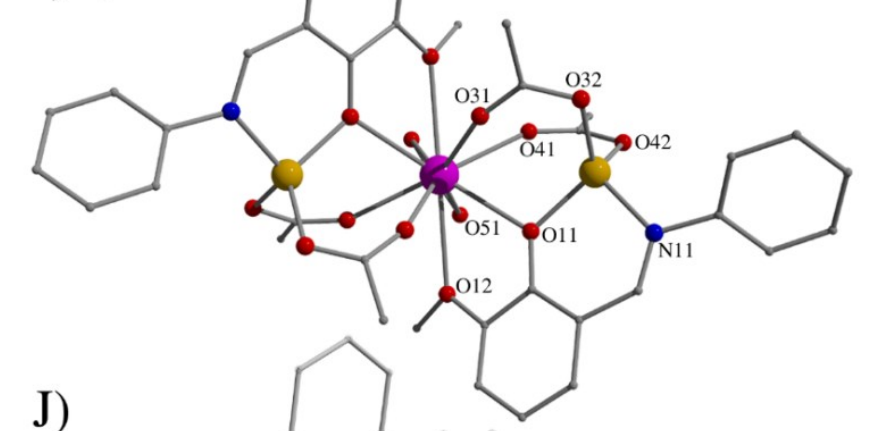

J)

Figure 1. Ball and stick representation of crystal structure of complexes $\mathbf{1}$ (A and B), 2 (C), 3 (G) and 4 (H). Figure D and E (for $\mathbf{1}$ ), F (for $\mathbf{2}$ ), I (for $\mathbf{3}$ ) and J (for $\mathbf{4}$ ) show the geometry around the corresponding lanthanide ions. Hydrogen atoms are omitted for clarity. Purple dotted bond represents the intramolecular hydrogen bonding in complex 1 and 2. Colour code: green = Dy, magenta = Pr, yellow = $\mathrm{Zn}$, red = O, blue = $\mathrm{N}$, grey = C. 
Hence the two $\mathrm{HL}$ ligands bound to the metal ion exist as a zwitterion, which has been unambiguously confirmed by NMR spectroscopy. ${ }^{[10 a, 11,14]}$ The lanthanide ion for both $\mathbf{1}$ and $\mathbf{2}$ are exclusively coordinated by oxygen donor atoms. The average Dy ${ }^{\prime \prime \prime}-\mathrm{O}$ and PrIII-O bond lengths are found to be $2.472 \AA$ and $2.306 \AA$, respectively. Selected bond lengths and bond angles are listed in Table 2.

Table 2. Selected bond length and bond angles for complexes 1-4

\begin{tabular}{|c|c|c|c|}
\hline $1 \mathrm{a}$ & Bond length $(\AA)$ & $1 \mathrm{a}$ & Bond length $(\AA)$ \\
\hline Dy(1)-O(11) & $2.272(4)$ & $\mathrm{Dy}(1)-\mathrm{O}(51)$ & $2.465(5)$ \\
\hline $\mathrm{Dy}(1)-\mathrm{O}(31)$ & $2.308(4)$ & $\mathrm{Dy}(1)-\mathrm{O}(41)$ & $2.495(4)$ \\
\hline $\mathrm{Dy}(1)-\mathrm{O}(62)$ & $2.434(6)$ & $\mathrm{Dy}(1)-\mathrm{O}(61)$ & $2.498(5)$ \\
\hline $\mathrm{Dy}(1)-\mathrm{O}(52)$ & $2.453(5)$ & $\mathrm{Dy}(1)-\mathrm{O}(12)$ & $2.702(4)$ \\
\hline $\mathrm{Dy}(1)-\mathrm{O}(42)$ & $2.465(6)$ & $\mathrm{Dy}(1)-\mathrm{O}(32)$ & $2.719(4)$ \\
\hline $1 b$ & Bond length $(\AA)$ & $1 b$ & Bond length $(\AA)$ \\
\hline $\mathrm{Dy}(2)-\mathrm{O}(111)$ & $2.271(4)$ & $\mathrm{Dy}(2)-\mathrm{O}(142)$ & $2.527(4)$ \\
\hline $\mathrm{Dy}(2)-\mathrm{O}(112)$ & $2.548(4)$ & $\mathrm{Dy}(2)-\mathrm{O}(151)$ & $2.505(4)$ \\
\hline $\mathrm{Dy}(2)-\mathrm{O}(141)$ & $2.463(4)$ & & \\
\hline 2 & Bond length $(\AA)$ & 2 & Bond length $(\AA)$ \\
\hline $\operatorname{Pr}(1)-\mathrm{O}(11)$ & $2.624(2)$ & $\operatorname{Pr}(1)-O(53)$ & $2.607(2)$ \\
\hline $\operatorname{Pr}(1)-\mathrm{O}(12)$ & $2.367(2)$ & $\operatorname{Pr}(1)-\mathrm{O}(62)$ & $2.660(2)$ \\
\hline $\operatorname{Pr}(1)-\mathrm{O}(31)$ & $2.727(2)$ & $\operatorname{Pr}(1)-O(63)$ & $2.532(2)$ \\
\hline $\operatorname{Pr}(1)-\mathrm{O}(32)$ & $2.403(2)$ & $\operatorname{Pr}(1)-\mathrm{O}(72)$ & $2.545(2)$ \\
\hline $\operatorname{Pr}(1)-\mathrm{O}(51)$ & $2.593(2)$ & $\operatorname{Pr}(1)-\mathrm{O}(73)$ & $2.545(2)$ \\
\hline 3 & Bond length $(\AA)$ & 3 & Bond length $(\AA)$ \\
\hline $\mathrm{Dy}(1)-\mathrm{O}(11)$ & $2.296(2)$ & Dy(1)-O(72) & $2.516(3)$ \\
\hline $\mathrm{Dy}(1)-\mathrm{O}(31)$ & $2.296(2)$ & $\mathrm{Dy}(1)-\mathrm{O}(32)$ & $2.561(2)$ \\
\hline Dy(1)-O(52) & $2.325(3)$ & $\mathrm{Zn}(2)-\mathrm{O}(51)$ & $1.997(2)$ \\
\hline Dy(1)-O(62) & $2.394(2)$ & $\mathrm{Zn}(2)-\mathrm{O}(31)$ & $2.516(3)$ \\
\hline $\mathrm{Dy}(1)-\mathrm{O}(61)$ & $2.416(3)$ & $\mathrm{Zn}(2)-\mathrm{N}(11)$ & $2.071(3)$ \\
\hline $\mathrm{Dy}(1)-\mathrm{O}(71)$ & $2.466(2)$ & $\mathrm{Zn}(2)-\mathrm{N}(31)$ & $2.096(3)$ \\
\hline Dy(1)-O(12) & $2.495(3)$ & & \\
\hline \multicolumn{4}{|c|}{ Bond Angle $\left({ }^{\circ}\right)$} \\
\hline $\mathrm{Zn}(1)-\mathrm{O}(11)-\mathrm{Dy}(1)$ & $102.6(2)$ & $\mathrm{Zn}(1)-\mathrm{O}(31)-\mathrm{Dy}(1)$ & $105.5(2)$ \\
\hline 4 & Bond length $(\AA)$ & 4 & Bond length $(\AA)$ \\
\hline $\operatorname{Pr}(1)-\mathrm{O}(31)$ & $2.440(4)$ & $\mathrm{Zn}(2)-\mathrm{O}(32)$ & $1.956(5)$ \\
\hline $\operatorname{Pr}(1)-\mathrm{O}(41)$ & $2.460(4)$ & $\mathrm{Zn}(2)-\mathrm{O}(11)$ & $1.964(4)$ \\
\hline $\operatorname{Pr}(1)-\mathrm{O}(11)$ & $2.509(4)$ & $\mathrm{Zn}(2)-\mathrm{O}(42)$ & $1.927(5)$ \\
\hline $\operatorname{Pr}(1)-\mathrm{O}(51)$ & $2.622(4)$ & $\mathrm{Zn}(2)-\mathrm{N}(11)$ & $2.007(5)$ \\
\hline $\operatorname{Pr}(1)-\mathrm{O}(12)$ & $2.734(4)$ & & \\
\hline \multicolumn{4}{|c|}{ Bond Angle $\left({ }^{\circ}\right)$} \\
\hline $\mathrm{Zn}(2)-\mathrm{O}(11)-\operatorname{Pr}(1)$ & $108.07(18)$ & & \\
\hline
\end{tabular}

While complexes 1 and 2 both crystallize in an orthorhombic crystal system and appear to be structurally analogous, the asymmetric unit (ASU) is distinctly different. For $\mathbf{2}$, there is one crystallographically distinct molecule found in the ASU. However for 1 , in addition to one crystallographically distinct molecule, another half molecule is present. These two molecules possess the same molecular formulae, however, the two molecules differ from each other by the relative orientation of ligands bound to the Dy III ion. One of the molecules reveals three chelating nitrate ions oriented in a near trigonal planar arrangement, with the two
Schiff base ligands, chelating via the phenoxo and methoxy sites being perpendicular to the near trigonal plane of the nitrate ions (1a, See Figure 1A). The second unique molecule, has the two $\mathrm{HL}$ ligands adjacent to each other, with the orientation of the chelating nitrates being distinctly different ( $\mathbf{1 b}$, see Figure 1B). Complexes $\mathbf{1 a}$ and $\mathbf{1 b}$ are, therefore, found to be geometric isomers, crystallizing in the same crystal lattice. To the best of our knowledge, such isomerism for a lanthanide complex is observed here for the first time, although there is precedence for coordination isomers. ${ }^{[15]}$ The different orientation of the nitrate ions in $\mathbf{1 a}$ and $\mathbf{1 b}$ is likely to have an influence on the magnetic properties of these complexes (vide infra).

In both 1 and 2, intra and intermolecular hydrogen bonding interactions are found to be operative (Figure 1 and Figure S1 of ESI). The iminium zwitterions are responsible for the intra molecular hydrogen bonding (average distance $\mathrm{NH} \ldots \mathrm{O}=1.8623$ $\AA$ ). In contrast, the nitrate ligands bound to the $\mathrm{Ln}^{\text {III }}$ ion facilitates intermolecular hydrogen bonding, which is clearly reflected in the packing diagram (for both 1 and 2) shown in Figure S1. The closest Dy"II...Dy"II and Pr"II...Pr ${ }^{\text {III }}$ distance is found to be 9.189 and $9.162 \AA$, respectively.

In contrast to $\mathbf{1}$ and $\mathbf{2}$, both $\mathbf{3}$ and $\mathbf{4}$ (Figure 1) are heterometallic complexes containing both lanthanide and diamagnetic $Z n^{\|}$ions. Single crystal X-ray diffraction reveals that 3 is a dinuclear Dy"l-Zn" complex (Figure 1G) which crystallizes in the triclinic space group, $P-1$ (Table 1). The ASU contains the entire complex. The zinc ion displays a distorted square pyramidal geometry with a $\left\{\mathrm{N}_{2} \mathrm{O}_{2}\right\}$ equatorial coordination sphere derived from the two deprotonated L-ligands. The apical position is occupied by an O-atom from the acetate ligand. The trivalent dysprosium ion displays a distorted tri-capped trigonal prismatic geometry, with a $\left\{\mathrm{DyO}_{9}\right\}$ coordination sphere (Figure 1I). The linkage between the $\mathrm{Zn}^{\prime \prime}$ and Dy"l' ions is provided by two phenoxo bridges and a carboxylate group, the latter displays the $\mu-\eta^{1}-\eta^{1}$ bonding mode. The methoxy group of the Schiff base ligand and the two chelating nitrate ions complete the coordination sphere of the Dy III ion. Similar structures have recently been reported by several authors using other compartmentalized Schiff base ligands. ${ }^{[3 c, 16]}$ The packing diagram of complex 3 reveals supramolecular interactions such as hydrogen bonding, which are facilitated by the nitrate ions (Figure S2).

Single crystal $X$-ray measurements reveal that $\mathbf{4}$ is a trinuclear $\mathrm{Zn}^{\text {II-}-P r}{ }^{\mathrm{III}}-\mathrm{Zn}$ "l complex. In contrast to $\mathbf{3}$, the $\operatorname{Pr}(\mathrm{III})$ ion in $\mathbf{4}$ is sandwiched between two $\mathrm{Zn}(\mathrm{II})$ ions, which deviate from linearity by $45^{\circ}\left(\angle \mathrm{ZnPrZn}=134.9(3)^{\circ}\right)$. Half of the molecule is found in the ASU (one $\mathrm{Zn}(\mathrm{II})$ and half of $\operatorname{Pr}(\mathrm{III})$ ) with the Prll ion lying on an inversion centre. The $\mathrm{Zn}(\mathrm{II})$ and $\operatorname{Pr}(\mathrm{III})$ ions are bridged by a phenoxo oxygen atom of the deprotonated ligand and two acetate ligands both displaying a $\mu-\eta^{1}-\eta^{1}$ coordination mode. The fourth coordination site of the $\mathrm{Zn}$ (II) ion is completed by the imine nitrogen derived from the Schiff base ligand. The $\mathrm{Zn}(\mathrm{II})$ ions display distorted tetrahedral geometries. The coordination sites of the $\operatorname{Pr}(\mathrm{III})$ ion are completed by methoxy and nitrate groups. The $\operatorname{Pr}($ III) ion maintains a similar geometry to the $\operatorname{Pr}(\mathrm{III})$ ion in 2, i.e. a bicapped distorted square anti-prism, with a $\left\{\mathrm{PrO}_{10}\right\}$ environment (Figure 1J). The intermolecular hydrogen 
bonding is effectively mediated through the nitrate and solvent molecules in the crystal lattice (Figure S2 of ESI).

\section{Static Magnetic Properties}

Direct current magnetic susceptibility measurements were performed on polycrystalline samples of 1 - 4, between 2 - $300 \mathrm{~K}$ in an applied magnetic field of $10 \mathrm{kOe}$. The room temperature (RT) $\chi_{M} T$ value for $\mathbf{1}$ and $\mathbf{3}$ is observed to be 14.06 and 14.11 $\mathrm{cm}^{3} \mathrm{~K} \mathrm{~mol}^{-1}$, respectively, while for 2 and 4 , a value of 1.61 and $1.62 \mathrm{~cm}^{3} \mathrm{~K} \mathrm{~mol}^{-1}$ is found, respectively (Figure 2).
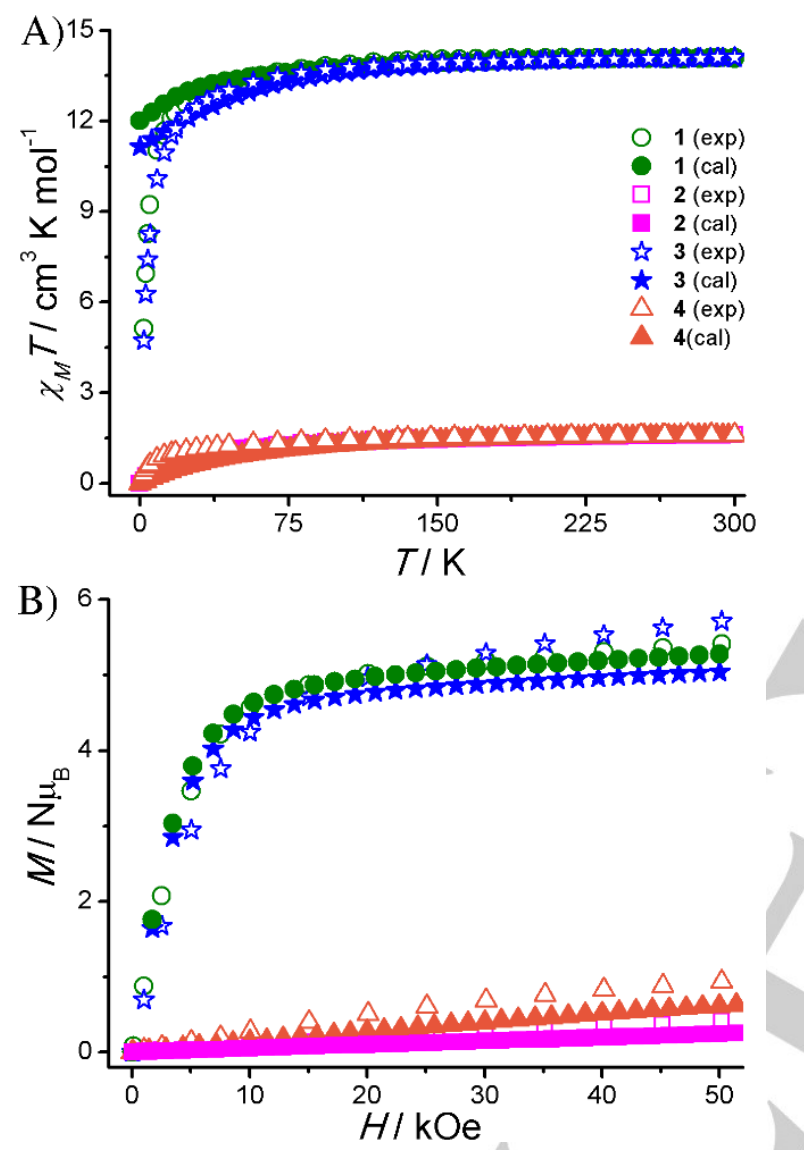

Figure 2. A) Temperature dependent direct current $\chi_{M} T$ plots of complexes 1 . 4 measured at $10 \mathrm{kOe}$. B) Field dependent magnetization measurements performed on $1-4$ at $2.0 \mathrm{~K}$. The open and filled symbols $(A)$ and $B)$ ) represent the data from experiment and computed data $(\chi M T(T)$ and $M(H))$ from ab initio calculations, respectively.

The experimentally observed $\chi_{M} T$ values for $\mathbf{1}-\mathbf{4}$ at $\mathrm{RT}$ are in excellent agreement with that expected for a Dy(III) $\left({ }^{6} \mathrm{H}_{15 / 2}, \mathrm{~g}=\right.$ $4 / 3)$ and $\operatorname{Pr}(\mathrm{III})$ ion $\left({ }^{3} \mathrm{H}_{4}, \mathrm{~g}=4 / 5\right)$ of 14.17 and $1.60 \mathrm{~cm}^{3} \mathrm{~K} \mathrm{~mol}^{-1}$, respectively. Upon reducing the temperature, the $\chi_{M} T$ product decreases gradually from RT down to $60 \mathrm{~K}$, for 1 and 3 . A similar situation is witnessed for complexes 2 and 4 . This observation is due to the depopulation of $m_{J}$ levels of the corresponding lanthanide ions as the temperature is reduced. Below $60 \mathrm{~K}$, in all four complexes, there is a drastic drop in the $\chi_{M} T$ value reaching a final value of $5.13,0.11,4.73,0.31 \mathrm{~cm}^{3} \mathrm{~K}$ $\mathrm{mol}^{-1}$ at $2.0 \mathrm{~K}$, for $1-4$, respectively. The sudden drop of the $\chi_{M} T$ value of all four complexes is a consequence of the magnetic anisotropy due to the intrinsic unquenched orbital angular momentum of the $\mathrm{Dy}(\mathrm{III})$ and $\operatorname{Pr}(\mathrm{III})$ ions. However, other factors such as intermolecular antiferromagnetic interactions and/or dipolar interactions are likely to contribute to the decrease of the $\chi_{M} T$ values at the lowest temperatures. Field dependent magnetization measurements at $2.0 \mathrm{~K}$ (Figure $2 \mathrm{~b}$ ) reveal that complexes $\mathbf{1}$ and $\mathbf{3}$, show a sudden linear increase in magnetization at low fields before deviating from linearity at higher fields, without saturation. The magnetization reaches a maximum value of 5.41 and $5.71 \mathrm{~N} \mu_{\mathrm{B}}$ at 5.0 Tesla for 1 and 3 respectively. This also suggests that both complexes possess a significant magnetic anisotropy. Moreover, this is further supported by the non-superimposable nature of the reduced magnetization curves (Figure S3). In contrast to $\mathbf{1}$ and $\mathbf{3}$, complexes 2 and 4 show a linear response over the entire magnetic field range.

\section{Dynamic Magnetic Properties}

In order to probe the magnetization relaxation dynamics of $\mathbf{1}$ - 4, alternating current magnetic susceptibility measurement were performed between 2 and $12 \mathrm{~K}$, using a 3.5 Oe oscillating magnetic field. In the absence of an applied dc magnetic field none of the complexes display frequency dependent out-ofphase susceptibility signals. This indicates that reversal of the magnetization orientation is extremely fast via quantum tunneling of the magnetization (QTM) through the low lying ground state multiplets.

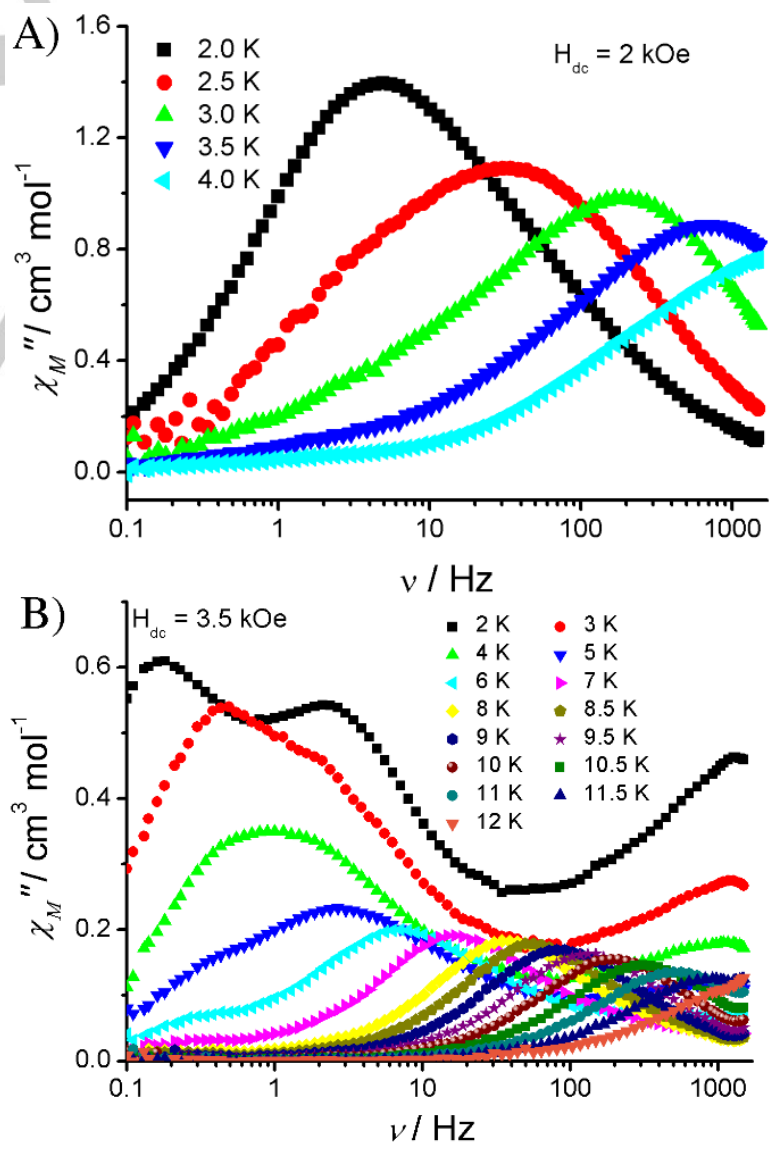

Figure 3. Frequency dependent out-of-phase susceptibility data measured for a polycrystalline sample of $\mathbf{1}$ (panel A) and $\mathbf{3}$ (panel B) at the indicated optimum dc bias field and temperatures. 

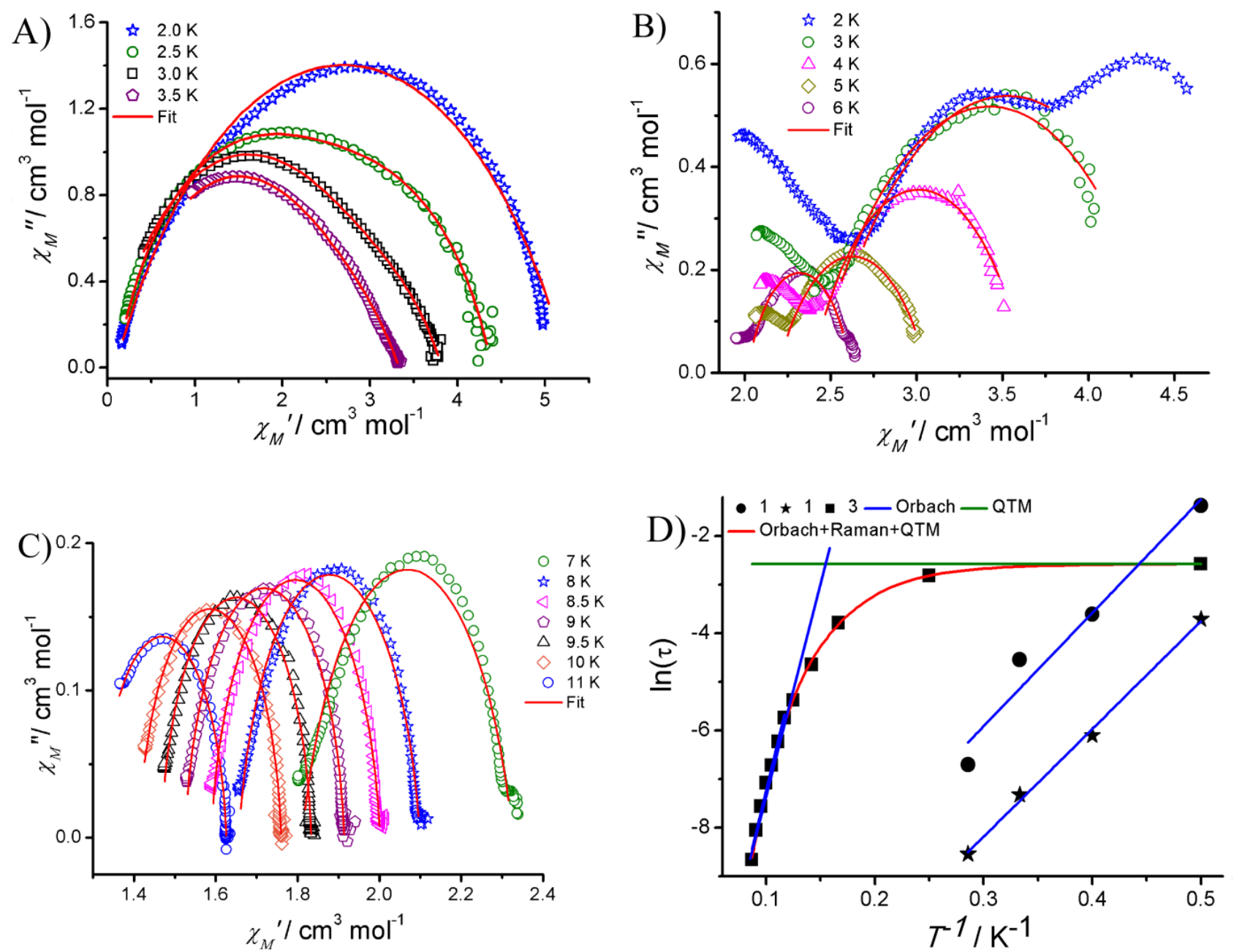

Figure 4. Cole-Cole plots of complex 1 (Panel A) and complex 3 (Panel B and C) measured at the indicated temperatures. The solid lines represent the best fit obtained for the parameters listed in Table S1 and S2. D) Arrhenius plots for complexes 1 and $\mathbf{3}$, the blue line represent the linear fit with Orbach process, green represents QTM and red represents non-linear fit including QTM, Orbach and Raman process (See text and eqn 3 for details)

This behavior is common for $\mathrm{Dy}(\mathrm{III}), \operatorname{Pr}(\mathrm{III})$ and heterometallic zinc containing complexes. $\left.{ }^{[3 \mathrm{e},} \mathrm{g}, 17\right]$ Upon application of an optimum bias dc magnetic field, however, both $1\left(\mathrm{H}_{\mathrm{dc}}=2 \mathrm{kOe}\right)$ and $3\left(\mathrm{H}_{\mathrm{dc}}=3.5 \mathrm{kOe}\right)$ reveal frequency and temperature dependent out-of-phase susceptibility signals (Figure 3 ). On the other hand, no out-of-phase susceptibility signals are observed for 2 and $\mathbf{4}$ even in the presence of dc bias field (data not shown). The broad signature of the out-of-phase susceptibility signals observed for 1 (Figure $3 \mathrm{~A}$ ) suggest that a distribution of relaxation behavior appears to be operative for this complex. While for 3 , it is clear that more than one magnetic relaxation pathway is operational. There could be several parameters responsible for the observation of multiple relaxation pathways in anisotropic lanthanide complexes, namely geometry assisted relaxation dynamics, for example $\left[\operatorname{Er}(\mathrm{COT})\left(\mathrm{Cp}^{*}\right)\right]$ and other $\left[\mathrm{Er}(\mathrm{COT})_{2}\right]$ complexes where the eclipsed and staggered conformation and/or $\angle \mathrm{COT}-\mathrm{Er}-\mathrm{Cp}^{*}$ angle is responsible for more than one relaxation process. ${ }^{[18]}$ The existence of direct and Orbach relaxation processes as witnessed in [Dy(DOTA)] complexes. ${ }^{[19]}$ Supramolecular interactions also appear to play a significant role in determining the orientation of the anisotropic axes, which in turn is correlated to its magnetization relaxation dynamics. ${ }^{[19 b]}$ Finally structural disorder within the same crystal, such as Jahn-Teller isomers of a [ $\mathrm{Mn}_{12} \mathrm{OAc}$ complex resulted in the observation of multiple relaxation processes due the different isomers having different molecular anisotropies. ${ }^{[20]}$ The observation of multiple relaxation processes are more common in polynuclear anisotropic lanthanide complexes, which is a consequence of the weak super exchange interactions mediated through the bridging ligands, with the exception of fewer reports. ${ }^{[17 b, 21]}$

The Cole-Cole plots of $\mathbf{1}$ and $\mathbf{3}$ are shown in Figure 4. Attempts to fit the Cole-Cole plot of $\mathbf{1}$ considering a single relaxation process using a generalized Debye model failed. Hence, we have fitted the Cole-Cole plot of $\mathbf{1}$, using a modified Debye model given in Eq. 1 and the parameters extracted are given in Table S1. 
$\chi_{A C}(\omega)=\chi_{S 1}+\chi_{S 2}+\frac{\chi_{T 1}-\chi_{S 1}}{1+\left(i \omega \tau_{1}\right)^{\left(1-\alpha_{1}\right)}}+\frac{\chi_{T 2}-\chi_{S 2}}{1+\left(i \omega \tau_{2}\right)^{(1-\alpha 2)}}$

Two merged relaxation processes occur as revealed by the Cole-Cole plot, which predict the presence of two closely spaced relaxation phases. The $\alpha_{1}$ value ranges from 0.002 to 0.46 and the $\alpha_{2}$ value ranges from 0.2 to 0.36 between $3.5 \mathrm{~K}$ to $2.0 \mathrm{~K}$. The increase in both $\alpha$ values at low temperatures designates that QTM process is likely to be operative at $2 \mathrm{~K}$. This elucidates why 1 does not display any SIM behavior under a zero bias dc field. The Arrhenius plot was constructed for both processes using the relaxation times extracted from Cole-Cole analysis and is shown in Figure 4D. The two processes were fitted considering only the thermally activated relaxation mechanism. The effective energy barriers are found to be $16.6 \mathrm{~cm}^{-1}\left(\tau_{0}=2.47 \times 10^{-6} \mathrm{~s}\right)$ and 15.8 $\mathrm{cm}^{-1}\left(\tau_{0}=3.6 \times 10^{-7} \mathrm{~s}\right)$. The two different relaxation process observed for 1 , is likely a consequence of the two geometrical isomers (1a and $\mathbf{1 b})$ present in the crystal lattice. However, to unambiguously confirm this, it is imperative to isolate a single crystal containing one of the geometric isomers only, using the $\mathrm{HL}$ ligand (or a similar ligand) and study its behavior. This work is currently in progress.

Interestingly for $\mathbf{3}$ which consists of a single unique molecule in its ASU the number of magnetization relaxation processes is greater than for 1 (Figure $3 \mathrm{~B}$ and Figures $4 \mathrm{~B}$ and $4 C)$. The multiple relaxation processes are highlighted from the isothermal field dependent ac susceptibility measurements (Figure S4). At the low magnetic field limit $(<0.025$ Tesla $) 3$ reveals a single fast relaxation process in the high frequency range. Upon increasing the magnetic field, a new slow relaxation process begins to appear in the $1-10 \mathrm{~Hz}$ frequency range at the expense of the fast relaxation process. Frequency dependent ac susceptibility measurements performed at the optimum dc bias field $(3.5 \mathrm{kOe})$ is shown in Figure 3B. At temperatures between $7-11 \mathrm{~K}$ one major relaxation is observed which is likely to be the thermally assisted Orbach process. Upon closer inspection the existence of a second relaxation process is also perceived at $9.5-11 \mathrm{~K}$ at the highest frequencies measured $\sim 1500 \mathrm{~Hz}$. Upon lowering the temperature, a third relaxation processes begins to dominate. From the Cole-Cole analysis of the relaxation data, we were not able to fit all the relaxation processes in the temperature range $2-11 \mathrm{~K}$, which might have given, distinctly, the relaxation times associated with each of the relaxation processes and their mechanism of relaxation (such as Direct or Raman or QTM etc.). ${ }^{[22]}$ Using the ac data over the entire temperature range, we were able to fit only the major relaxation process using a generalized Debye model (equation 2) and the extracted parameters are listed in Table S2.

$$
\chi_{A C}(\omega)=\chi_{S}+\frac{\chi_{T}-\chi_{S}}{1+(i \omega \tau)^{(1-\alpha)}} .
$$

The $\alpha$ values (0.084-0.408 for $2-11 \mathrm{~K}$ ) are significantly smaller at higher temperature which increases gradually upon decreasing the temperature, emphasizing a distribution of relaxation time. A perfect fit could not be obtained, however, even for the major higher temperature relaxation process, which further stresses the existence of multiple relaxation phases.
Using the relaxation times extracted from the Cole-Cole plots, we have constructed an Arrhenius plot for $\mathbf{3}$ which is shown in Figure 4D. Below $6 \mathrm{~K}$ we notice a deviation from linearity again implying that multiple relaxation processes are operational. The data over the entire temperature range was modelled by considering various relaxation processes reported in the literature ${ }^{[5 a, 23]}$ using Eq. 3.

$$
\frac{1}{\tau}=\frac{1}{\tau_{Q T M}}+A H^{2} T+C T^{n}+\tau_{0}^{-1} \exp \left(\frac{-U_{e f f}}{k_{B} T}\right)
$$

The first term on the right hand side of Eq. 3 corresponds to the relaxation process through QTM, the second term denotes the direct process, third term represent relaxation via a Raman process and the final term corresponds to an Orbach relaxation mechanism. To fit the Arrhenius plot of $\mathbf{3}$, it is not necessary to use all the relaxation processes listed in equation 3 . The best fit to the data was obtained by only considering the Orbach $\left(U_{\text {eff }}=\right.$ $\left.83 \mathrm{~cm}^{-1}, \tau_{0}=1.36 \times 10^{-8} \mathrm{~s}\right)$, Raman $\left(\mathrm{C}=0.00203 \mathrm{~s}^{-1} \mathrm{~K}^{-3}\right.$ and $\mathrm{n}=$ 5.39 ) and QTM ( $\tau_{\text {QTM }}=0.076 \mathrm{~s}$ ) processes (Figure $4 \mathrm{D}$ (red trace)).

To understand the influence of the intermolecular dipolar interaction(s) for 3 , we have attempted to synthesize its diamagnetic analogue (i.e. Lu ${ }^{\prime \prime \prime}-Z n^{\prime \prime}$ or $Y^{\prime \prime \prime}-Z n^{\prime \prime}$ ) in which the paramagnetic complex would be co-crystalized within the diamagnetic matrix. Unfortunately, despite our best efforts, we failed to isolate the isostructural diamagnetic complex. In all cases either a mono- or tri-nuclear zinc(II) compound was isolated (data not shown). We therefore sought an alternative approach to minimize the inter-complex dipolar interaction. Hence, we performed solution based ac susceptibility measurements which is equivalent to dilution in the solid state using a diamagnetic matrix. Before performing such measurements, we examined the solution stability in dichloromethane, using Matrix Assisted Laser Desorption Ionization (MALDI, Figure S5) mass spectrometry. The results revealed, via a $\mathrm{m} / \mathrm{z}$ peak at 863 , that the solid state structure is stable in solution (Figure S5 of ESI). The solution ac susceptibility measurement of $\mathbf{3}$ at the optimum dc bias field of 1 $\mathrm{kOe}$ again reveals frequency dependent out-of-phase susceptibility signals indicative of the presence of slow magnetization relaxation. The measurement also proves that the magnetization relaxation is purely of molecular origin. The observation of broad $\chi \mathrm{M}$ " signals implies that there are multiple relaxations processes, as expected (data not shown). The ColeCole plot constructed from solution measurements further supports the existence of multiple relaxation processes (Figure $5)$. Note that the existence of multiple relaxation processes for various mononuclear Dy(III) complexes has previously been reported by several research groups. ${ }^{[23-24]}$ By considering only the major relaxation process and using a generalized Debye equation (Eq. 2) reasonable fits of the Cole-Cole data could be obtained, with $\alpha$ ranging between 0.48-0.89 (Figure 5 and Table S4 of ESI). The very large $\alpha$ values indicate a significant distribution of the relaxation time. Again, we have made use of the relaxation times extracted from Cole-Cole data fits (shown in figure 5) to construct the Arrhenius plot. The data was fitted 
(using Eq. 3) by considering a thermally assisted relaxation process $\left(U_{\text {eff }}=89.2 \mathrm{~cm}^{-1} ; \tau_{0}=1.0447 \times 10^{-11} \mathrm{~s}\right)$, a Raman $(C$ $=0.00611 ; n=7.1062)$ and a QTM ( $\left.\tau_{\text {QTM }}=0.0768 \mathrm{~s}\right)$ relaxation mechanism. A slightly higher thermal energy barrier is observed for the diluted sample of $\mathbf{3}$ compared to solid state sample. This confirms the non-negligible contribution that the dipolar interaction plays in the magnetization relaxation dynamics.
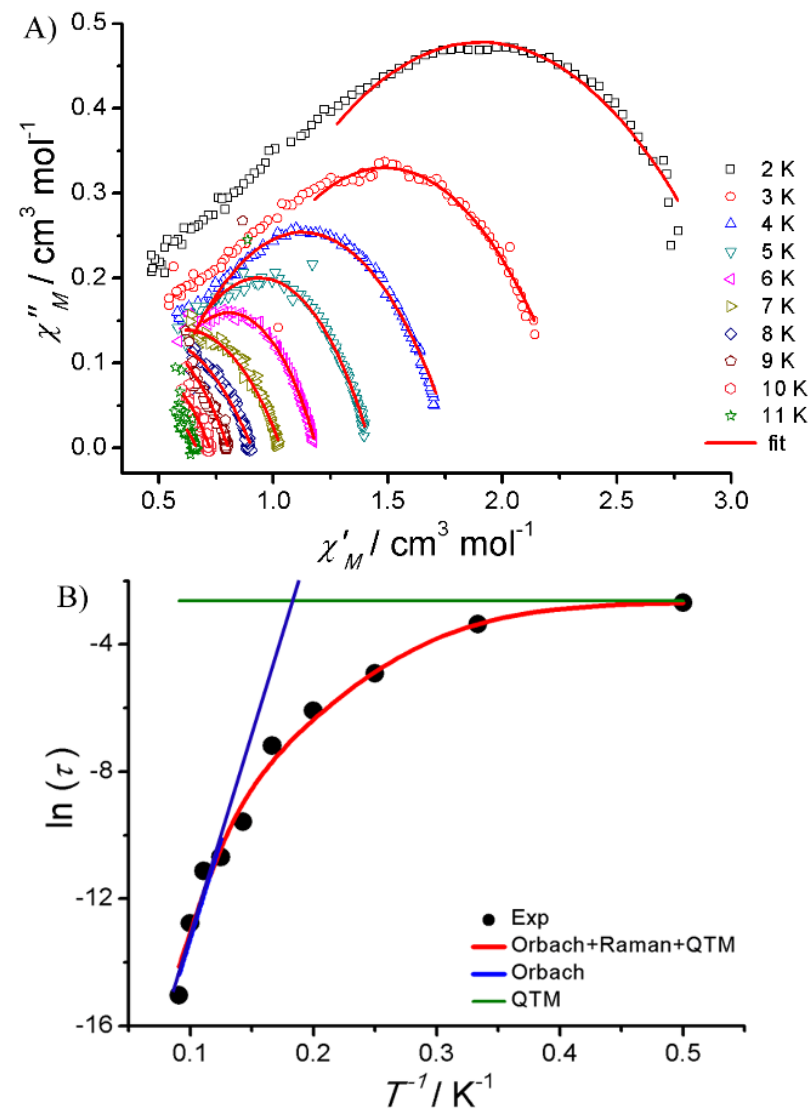

Figure 5. A) Cole-Cole plot recorded for the solution sample of 3 in the presence of $10 \mathrm{kOe}$ static magnetic field at the indicated temperatures. The solid red line represents the best fit obtained by considering a generalized Debye model using the parameters described in Table S4 of the ESI. B) Arrhenius plot for 3 constructed using the $\tau$ values obtained from fitting of Cole-Cole plot. The solid red line represents the best fit obtained by considering Orbach, Raman and QTM relaxation processes.

Complexes $\mathbf{1}$ and $\mathbf{3}$ can be considered magnetically as mononuclear entities (the $\mathrm{Zn}$ (II) ion in $\mathbf{3}$ is diamagnetic) and due to the structural similarities the observation of a fivefold increase of the $U_{\text {eff }}$ parameter for 3 , compared to 1 is quite surprising. Several unrelated literature reports claim that $\mathrm{Zn}$ (II) containing Dy(III) complexes display better SIM or SMM behaviour than the parent analogue made by point charged ligands, however no theoretical calculations were performed in these studies to help understand the observed behavior (Table 4 and Table S3 in ESI).

\section{Theoretical Calculations}

To understand the five-fold increase in the $U_{\text {eff }}$ barrier for the complex containing the diamagnetic $\mathrm{Zn}$ (II) ion, we probed the influence the $\mathrm{Zn}$ (II) ions have on the electronic structure and therefore the magnetic anisotropy of the $\mathrm{Ln}$ (III) ions, using stateof-the-art ab initio calculations. We have undertaken detailed post-Hartree-Fock ab initio calculations on all complexes $\mathbf{1 a}, \mathbf{1} \mathbf{b}$, 2, 3 and 4 to validate the experimental observations using the MOLCAS $7.8^{[25]}$ code, as this has proved its aptness on several

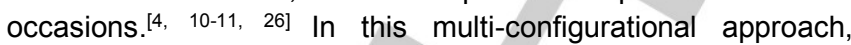
relativistic effects are treated using the Douglas-Kroll Hamiltonian. For the generation of basis sets, scalar terms were included which have been used to determine the spin-free wave functions and energies through the use of the complete active space self-consistent field (CASSCF) ${ }^{[27]}$ method. Spin-orbit coupling has been taken into account using the RASSI-SO ${ }^{[28]}$ method which uses CASSCF wave functions as the basis sets and multi-configurational wave functions as input states. The resulting wave functions and energies of the molecular multiplets were used for the calculation of the anisotropic magnetic properties and $g$-tensors of the lowest state using a specially designed routine SINGLE_ANISO. ${ }^{[29]}$ As a consequence, the magnetic properties of a single magnetic ion are calculated by a fully $a b$ initio approach, in which the spin-orbit coupling is considered non-perturbative. We have employed atomic natural (ANO-RCC) basis set for the calculation of the $g$-tensors embedded in the MOLCAS basis set library. The following contraction scheme has been employed [8s7p5d3f2g1h] for Dy, [5s4p2d1f] for Zn, [3s2p1d] for N, [3s2p1d.] for O, [3s2p] for C and [2s] for $\mathrm{H}$ during the computation of the $g$ tensors for complex 1a, 1b and 3, while [7s6p4d2f] for Pr, [5s4p2d] for $\mathrm{Zn}$, [3s2p] for $\mathrm{N},[3 \mathrm{~s} 2 \mathrm{p}]$ for $\mathrm{O},[3 \mathrm{~s} 2 \mathrm{p}]$ for $\mathrm{C}$ and [2s] for $\mathrm{H}$ during the computation of the $g$ tensors for complexes 2 and 4 . The ground state atomic multiplicity of Dy'III is ${ }^{6} \mathrm{H}_{15 / 2}$ which results in eight low-lying Kramer's doublets (KD). CASSCF calculation comprises an active space of nine active electrons in seven active orbitals (CAS $(9,7)$ ). CASSCF calculations have been performed with 21 sextets which arise from $\left({ }^{6} \mathrm{H},{ }^{6} \mathrm{~F}\right.$ and $\left.{ }^{6} \mathrm{P}\right)$ multiplets. In the next step we have mixed these CASSCF computed spin-free states via the RASSI module to obtain the spin-orbit states. Here we have performed RASSI calculations with 21 sextet states which arise from $\left({ }^{6} \mathrm{H},{ }^{6} \mathrm{~F}\right.$ and $\left.{ }^{6} \mathrm{P}\right)$ multiplets and extracted the relative energies of the KDs. In the last step we have used the SINGLE_ANISO code implemented in the MOLCAS program to compute the $g$-tensors. We and others have shown that 21 roots are good enough to obtain the $g$ tensors in Dy(III) complexes, ${ }^{[30]}$ thus this methodology has been employed throughout. The ground state atomic multiplicity of $\mathrm{Pr}$ III is ${ }^{3} \mathrm{H}_{4}$ which results in nine singlets for complex 2 , while seven singlets and one doublet is observed for 4 . The CASSCF calculation comprises an active space of two active electrons in seven active orbitals $(\mathrm{CAS}(7,2))$. Here we have computed 21 triplets and 28 singlets in the $\mathrm{Cl}$ procedure and then mixed them in the RASSI-SO module to obtain the spin-orbit states and the relative $g$-tensors. From these calculations, we have computed the static $d c$ magnetic properties such as the magnetic susceptibility as a function of temperature and the molar magnetization as a function of magnetic field. The computed static $d c$ properties are in the excellent agreement with experimental observations, which adds confidence to computed parameters (Figure 2 and Figure S6, S7). The parameters 
derived from the calculations can be directly taken as a tool to assess the SMM properties. For complex 1, two different mononuclear units are present in the ASU, hence calculations are performed on both complexes labelled as $\mathbf{1 a}$ and $\mathbf{1 b}$. The computed energies for the eight low-lying Kramer's doublets (KDs) span $559.7 \mathrm{~cm}^{-1}$ and $455.8 \mathrm{~cm}^{-1}$ for $\mathbf{1 a}$ and $\mathbf{1 b}$, respectively.

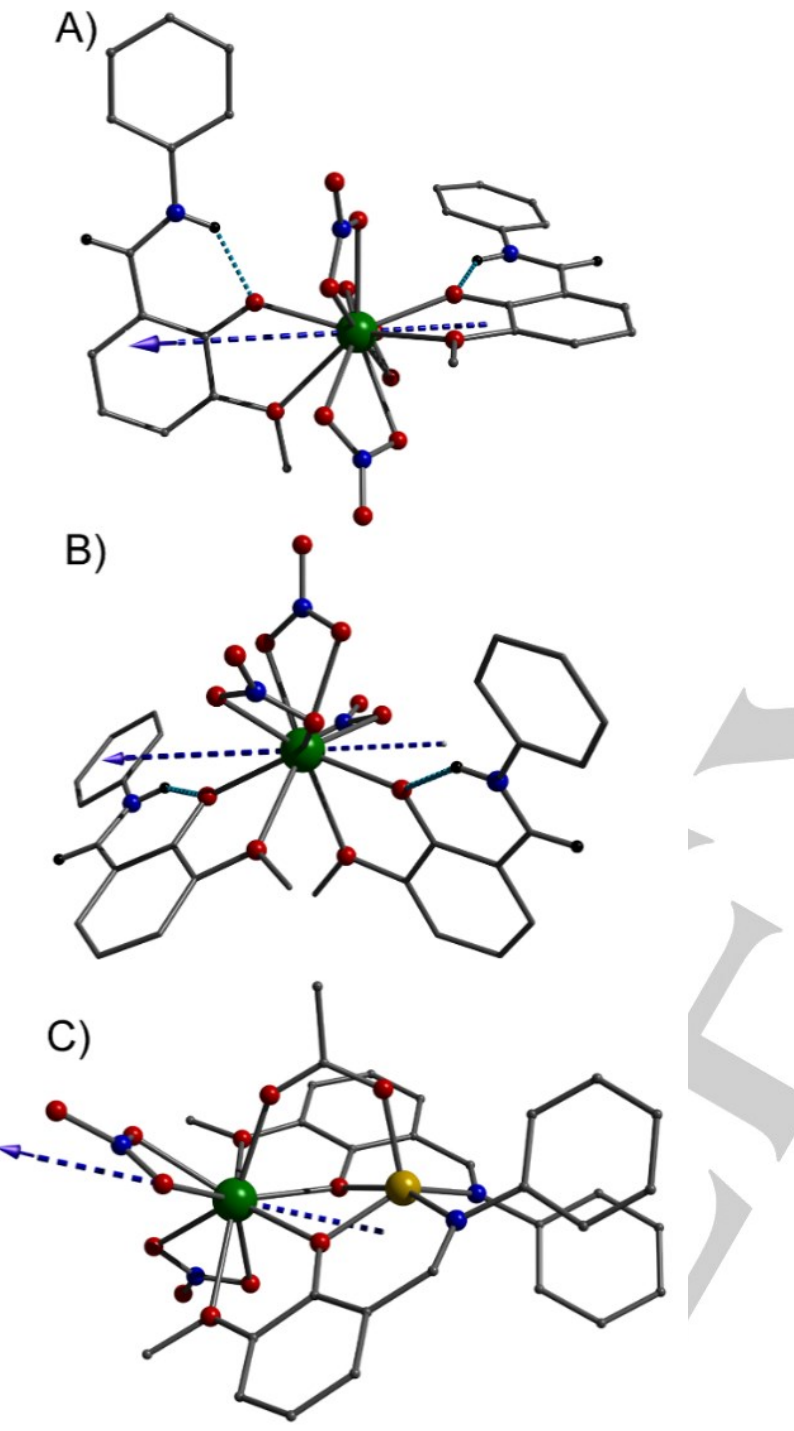

Figure 6. The molecular structure of complexes A) 1a B) 1b C) 3 and showing the orientation of computed easy axis anisotropy. Color code: Green = Dy, Yellow $=\mathrm{Zn}$, Red $=\mathrm{O}$, Blue $=\mathrm{N}$, grey $=\mathrm{C}$

The computed $g$-tensors are found to be $\left[g_{x x}=0.020, g_{y y}=\right.$ 0.036, $\left.g_{z z}=19.443\right]$ for $1 \mathbf{a}$ and $\left[g_{x x}=0.081, g_{y y}=0.121, g_{z z}=\right.$ 19.092] for $\mathbf{1 b}$, which is strongly axial for both species, but are not pure Ising in nature (where $g_{x x}=g_{y y}=0$ ) (see Table S5-S6 and Figure 6, Figure S8-S9). The trend in the computed $g$-tensor of the eight lowest KDs represent typical features of lowsymmetric complexes. The computed energy of the first excited Kramers doublet, which often correlates to the height of the energy barrier $\left(U_{\text {eff }}\right)$ in low-symmetric lanthanide single ion magnets, is found to be $76 \mathrm{~cm}^{-1}$ and $46 \mathrm{~cm}^{-1}$ for $1 \mathrm{a}$ and $\mathbf{1 b}$, respectively. A significant variation in the ground to first-excited state gap for $\mathbf{1 a}$ and $\mathbf{1 b}$ suggests that this separation is extremely sensitive to small structural changes. The computed crystal field (CF) parameters show large and negative $B_{2}^{0}$ values representing the isolation of the $| \pm 15 / 2\rangle$ as the ground state. Wave function decomposition analysis suggests that the ground state in both cases is predominantly $| \pm 15 / 2\rangle$, however, the extent of mixing is significantly large; $(0.93| \pm 15 / 2\rangle-0.31| \pm 11 / 2\rangle$ $0.12| \pm 11 / 2\rangle)$ in $\mathbf{1 b}$, compared to $(0.96| \pm 15 / 2\rangle+0.12| \pm 9 / 2\rangle)$ for 1 a. Thus both the geometries are not ideally suited towards isolating a pure $| \pm 15 / 2\rangle$ ground state, however, complex 1 a is relatively better than complex $\mathbf{1 b}$. The SMM performance of complex 1 must therefore be considered as a combination of the properties of both complexes. It is important to note here that magnetic exchange, mediated through a dipolar interaction is one of the key factors for diminishing the SMM characteristic in complexes such as 1 (see later).

To elucidate the mechanism of magnetic relaxation, we have developed the ab initio calculated blockade barrier by computing the transversal magnetic moments between the connecting pairs (Figure 7). Due to the lack of any symmetry present for complex 1, the magnetic moment between the $| \pm ; 1\rangle$ pair is significantly large (on the order of $10^{-2} \mu_{B}$ ) suggesting QTM is operative at the ground state KD (generally $10^{-5} / 10^{-6} \mu_{\mathrm{B}}$ for complete quenching of QTM). The extent of QTM is significantly larger for complex $\mathbf{1 b}$, compared to $\mathbf{1 a}$ due to an unfavorable ligand field arrangement (vide infra). The QTM can best be described by the crystal field parameters, as they are highly sensitive to the structural distortions and serve as a guide for analyzing the QTM effects. From Table 3 (see also Table S7), it is evident that for both complexes the axial $B_{2}^{0}$ term is only marginally larger compared to the non-axial terms $B_{2}^{2}, B_{2}^{1}, B_{4}^{-1}$, which implies that QTM is present due to structural distortions. The axial term in complex $\mathbf{1 a}$ is relatively large compared to $\mathbf{1 b}$, representing the large QTM at the ground state of $\mathbf{1 b}$, in line with $a b$ initio calculations. The orientation of the $g$-tensor is tilted in the direction of minimum electrostatic potential, which are found to be different for both complexes (Figure $6 \mathrm{~A}$ ) and B)). Thus the difference in the magnetic properties of complexes $\mathbf{1 a}$ and $\mathbf{1 b}$ can be rationalized based on the number/nature of donor ligands on the axial/equatorial positions. For $1 \mathrm{a}$, three $-\mathrm{NO}_{3}{ }^{-}$ligands form a distorted equatorial ligand field, while four $-\mathrm{O}$ atoms occupy the axial positions. One of the $-\mathrm{O}$ donor ligands of each - $\mathrm{L}^{-}$ligand is the strongly coordinated to the Dy(III) ion, compared to other bond lengths, indicating a significant axial ligand field offered by that particular Dy-O bond. Moreover, these -O donor atoms possess the greatest negative charge, thus, the shorter Dy-O axial bond lengths suppress the adverse effect caused by other Dy-O bonds at the equatorial sites. This arrangement of ligands results in the stabilization of $m_{J}| \pm 15 / 2\rangle$ as the ground state. In stark contrast, complex $\mathbf{1 b}$, possesses an equatorial plane consisting of -three $-\mathrm{NO}_{3}{ }^{-}$ligands and one $-\mathrm{O}$ donor atom from each $-\mathrm{L}^{-}$ligand. The two remaining $-\mathrm{O}$ atoms of the each $\mathrm{L}^{-}$ligand are found in axial positions. Thus the Dy(III) ion in complex 1b faces more repulsion from the unfavorable 
equatorial position leading to the stabilization of $| \pm 15 / 2\rangle$, however with lower-lying excited states. The arguments presented above based on the ligand field effects are reflected in the computed $a b$ initio blockade barrier (see figure 7 for details).
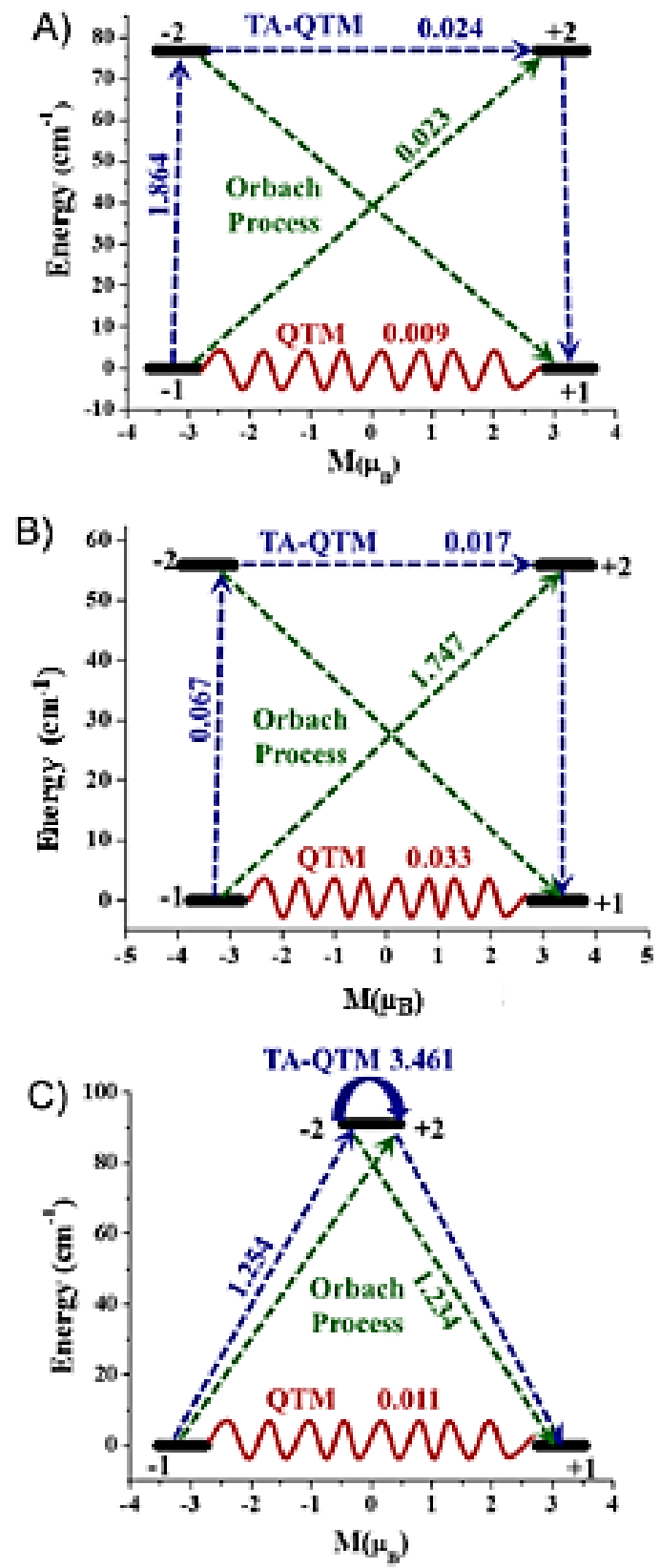

Figure 7. Ab initio computed matrix elements between the connecting pairs (ground state and first excited state) in complex 1a (left), 1b (middle) and complex 3 (bottom). The thick black line indicates the Kramer's doublets (KDs) as a function of magnetic moment. The dotted green lines show the possible pathway of the Orbach (Raman) process. The zig-zag lines connecting the ground state KDs represent the QTM. The dotted blues lines show the thermally activated-QTM via the first excited state.
The calculations therefore suggest significant anisotropy barriers (1a and $\mathbf{1 b}$ ), however the presence of a substantially large QTM relaxation in the ground state is the reason behind a lack of zero field SMM behavior for 1 . As there is a significant barrier present, ac measurements in the presence of an applied dc magnetic field allow the energies of the magnetic microstates to be perturbed, leading to a partial quenching of the tunneling mechanism and slow relaxation of the magnetization is observed. Despite the application of external magnetic field, the QTM could not be completely quenched as the experimental value gives a height of $\sim 20 \mathrm{~cm}^{-1}$ contrary to the theoretical value of $60-70 \mathrm{~cm}^{-1}$

In order to understand the experimentally determined fivefold increase in the barrier height of 3 , compared to 1 , and to fully understand the relaxation dynamics we have also performed CASSCF+RASSI calculations on complex 3. The computed energy window of eight low-lying KDs for complex 3 spans a range of $396 \mathrm{~cm}^{-1}$. The computed $g$-tensors for the ground state $\mathrm{KD}$ is found to be $\left[g_{\mathrm{xx}}=0.02, g_{y y}=0.04\right.$ and $\left.g_{z z}=18.82\right]$ which again reflects the presence of an Ising anisotropy which is not pure in nature (Table S8 and Figure S10 in ESI).

Table 3. SINGLE_ANISO computed crystal field parameter for complexes 1 and 3.

\begin{tabular}{|c|c|c|c|c|}
\hline & & $1 a$ & $1 \mathrm{~b}$ & 3 \\
\hline k & $\mathrm{Q}$ & $B_{k}^{q}$ & $B_{k}^{q}$ & $B_{k}^{q}$ \\
\hline & -2 & $-0.633 E+00$ & $0.296 \mathrm{E}-02$ & $0.125 E+01$ \\
\hline & -1 & $0.194 E+01$ & $0.156 E+01$ & $0.248 E+00$ \\
\hline 2 & 0 & $-0.239 E+01$ & $-0.218 E+01$ & $-0.125 E+01$ \\
\hline & 1 & $-0.643 E+00$ & $0.109 E-01$ & $0.691 E+00$ \\
\hline & 2 & $-0.757 E+00$ & $0.110 E+01$ & $-0.654 E+00$ \\
\hline \multirow{9}{*}{4} & -4 & 0.401E-02 & $-0.442 E-04$ & 0.117E-01 \\
\hline & -3 & $-0.430 E-02$ & 0.653E-02 & $-0.288 E-01$ \\
\hline & -2 & -0.279E-02 & $-0.244 E-04$ & -0.192E-02 \\
\hline & -1 & $-0.305 E-01$ & $-0.530 E-03$ & -0.647E-02 \\
\hline & 0 & -0.828E-03 & 0.282E-03 & $-0.215 E-03$ \\
\hline & 1 & $0.183 E-02$ & $-0.295 E-04$ & $-0.860 E-02$ \\
\hline & 2 & 0.593E-02 & $-0.811 E-02$ & $0.176 \mathrm{E}-01$ \\
\hline & 3 & 0.842E-02 & 0.979E-05 & $0.226 \mathrm{E}-01$ \\
\hline & 4 & $0.547 \mathrm{E}-02$ & $-0.616 \mathrm{E}-02$ & $-0.633 E-02$ \\
\hline \multirow{13}{*}{6} & -6 & $-0.167 E-03$ & $-0.113 E-05$ & $-0.124 \mathrm{E}-03$ \\
\hline & -5 & $-0.322 E-04$ & 0.130E-02 & $0.165 E-03$ \\
\hline & -4 & $0.311 \mathrm{E}-03$ & 0.273 E-05 & $-0.545 E-05$ \\
\hline & -3 & $0.255 \mathrm{E}-03$ & $-0.918 E-04$ & $0.135 \mathrm{E}-03$ \\
\hline & -2 & $-0.971 E-05$ & $0.143 E-05$ & $0.254 \mathrm{E}-03$ \\
\hline & -1 & $0.227 E-03$ & $-0.247 E-03$ & -0.609E-04 \\
\hline & 0 & $0.155 E-04$ & $0.136 \mathrm{E}-04$ & $-0.181 E-04$ \\
\hline & 1 & $0.327 \mathrm{E}-04$ & $0.935 E-06$ & $0.226 \mathrm{E}-03$ \\
\hline & 2 & 0.847E-04 & 0.310 E-03 & 0.677E-05 \\
\hline & 3 & -0.450 E-03 & 0.170E-06 & $0.366 \mathrm{E}-03$ \\
\hline & 4 & $-0.433 E-04$ & $0.329 E-03$ & $0.936 \mathrm{E}-04$ \\
\hline & 5 & 0.137E-02 & $-0.133 E-04$ & $0.244 \mathrm{E}-03$ \\
\hline & 6 & $0.766 \mathrm{E}-04$ & $-0.546 \mathrm{E}-04$ & $-0.324 E-04$ \\
\hline \multicolumn{5}{|c|}{$\begin{array}{l}\text { a) The major components in the table are shown in boldface font. b) The } \\
\text { crystal field Hamiltonian parameter is defined as } \sum \sum_{k=-q}^{q} B_{k}^{q} \widetilde{O}_{k}^{q} \text {, where } B_{k}^{q} \\
\text { is the crystal field parameter and } \widetilde{O}_{k}^{q} \text { is the extended Stevens operator. } \\
\text { Quantization axis is chosen to be the main magnetic axes of the ground } \\
\text { Kramer Doublet. }\end{array}$} \\
\hline
\end{tabular}

The ground state magnetization axis is tilted towards one of the $\left(-\mathrm{NO}_{3}\right)^{-}$ligands with an angle of 20.7 degrees from the $\mathrm{Zn}-\mathrm{Dy}$ molecular axis. The first excited state is $91 \mathrm{~cm}^{-1}$ higher in energy from the ground state, and the mismatch between the ground 
and excited $g_{z z}$ orientation sets this as the $U_{c a l}$ value for magnetic relaxation. Similar to complex $\mathbf{1}$, the computed $\mathrm{CF}$ parameters show large negative $B_{2}^{0}$ parameters, which represent the isolation of $| \pm 15 / 2\rangle$ as the ground state. Again QTM is expected to be present for $\mathbf{3}$, as a significant transverse component is found in the ground state KD. This is in line with the experimental data, where no SMM behavior is observed in zero magnetic field (see Tables S5-S7). The $U_{c a l}$ value obtained for 3 is in close agreement with the experimental data $\left(91 \mathrm{~cm}^{-1}\right.$ (calc.) vs $83 \mathrm{~cm}^{-1}$ (exp.)). Again we probed the mechanism of relaxation using the calculated parameters. Wave function decomposition analysis suggests that the ground state is predominantly $| \pm 15 / 2\rangle:-0.90| \pm 15 / 2\rangle+0.20| \pm 9 / 2\rangle+0.19| \pm 11 / 2\rangle$ with a slight mixing from other higher excited states. This is the reason behind the presence of the non-negligible transverse anisotropy. Interestingly, the first excited KD is predominantly $\pm 1 / 2\rangle$ with significant mixing from the other excited states. The computed ab initio blockade barrier reflects a significant transition magnetic moment of $0.01 \mu_{\mathrm{B}}$ between the $| \pm ; 1\rangle$ pair, which clearly suggests the presence of non-negligible QTM at the ground state. The non-negligible QTM is the reason no SMM behavior is observed at zero magnetic field. Again, as with $\mathbf{1}$, the application of an external field lifts the degeneracy of the ground microstates quenching QTM in the ground state resulting in magnetic relaxation via a thermally activated process.

We now turn to answering what role the $\mathrm{Zn}$ (II) ion plays (if any) in increasing the $U_{\text {eff }}$ value in this class of complex ( 3 vs 1 ). DFT calculations reveal that the bridging phenoxo oxygen atoms in $\mathbf{3}$ have greater negative charges compared to that of the coordinated oxygen atoms in 1 (-0.73 vs. -0.3 , see Table S9-S11 and Figure S11-S13). The presence of the $\mathrm{Zn}^{2+}$ ion leads to a larger charge polarization on the oxygen atoms, which in turn induces a large electrostatic interaction on the lanthanide ion. This eventually leads to the destabilization of excited states increasing the ground-to-first-excited state energy gap. This invariably suggests that the presence of a diamagnetic ion in the vicinity of the $\operatorname{Ln}(\mathrm{III})$ coordination environment is likely to help to enhance the $U_{\text {eff }}$ barrier.

This polarization effect has been witnessed earlier in $\{\mathrm{Na}[\mathrm{Dy}(\mathrm{DOTA})]\}$ and $\left\{\mathrm{Dy}_{4} \mathrm{~K}_{2}\right\}$ complexes. ${ }^{[1 \mathrm{a},}$ 19, 31] The point is further validated by the fact that all reported $\left\{Z n^{\prime \prime}-D y^{\prime \prime \prime}\right\}$ molecules possess more desirable SMM properties i.e. higher $U_{\text {eff }}$ parameters than structurally similar mononuclear Dy"l' analogues (see Table 4 and Table S3). We have therefore used these data found in the literature to find a correlation of the computed $U_{\text {eff }}$ values to specific structural parameters. As with complex $\mathbf{3}$, the literature reported structures maintain axiality in the ground state anisotropy, with a small transverse component. Although the complexes given in Table 4 are structurally similar to each other and analogous to complex 3 , there are significant differences in the anisotropy barrier.

First we cross checked the role of the Dy"l coordination number (nine vs. ten coordinate for the Dy"I and Zn"-Dy"II complexes). For this we analyzed the ten coordinate Dy(III) which is structurally similar to that of complex $\mathbf{1}$ and $\mathbf{3}$ in a

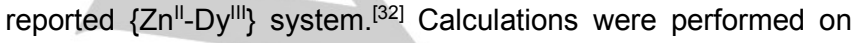
the X-ray structure of $\left[\mathrm{Zn}^{\prime \prime} \mathrm{Dy} \mathrm{y}^{\prime \prime \prime}\left(\mathrm{NO}_{3}\right)_{3} \mathrm{~L}\left(\mathrm{H}_{2} \mathrm{O}\right)\right]$ (Where $\mathrm{H}_{2} \mathrm{~L}=1,3$ - propanediylbis(2-imi-nomethylene-6-methoxy-phenol, Reference Code: IWURAU) for comparative studies.

Table 4. Ab initio computed list of $\mathrm{ZnDy}$ complexes (coordination number of Dy is nine) which are structurally related to complex $\mathbf{3}$ available in Cambridge structural database (CSD).

As evident from the Table S12, the ground state is axial but lacks pure Ising type with $g_{x}=0.03, g_{y}=0.08$ and $g_{z}=17.87$ (see Figure $\mathrm{S} 15 \mathrm{~A}$ for ground state $\mathrm{g}_{\mathrm{z}}$ tensor alignment). The principal $g$ tensor of the first excited multiplet is tilted by $62.5^{\circ}$ with respect to the ground state $g_{z}$ orientation. This outlines the computed energy barrier for the studied complex to be $98.3 \mathrm{~cm}^{-1}$. Next we have elucidated the mechanism for the relaxation of magnetization (see Figure S15B). QTM within the ground state

\begin{tabular}{|c|c|c|c|c|c|c|c|}
\hline \multirow[t]{2}{*}{$\begin{array}{l}\text { S. } \\
\text { No }\end{array}$} & \multirow[t]{2}{*}{$\begin{array}{l}\text { Molecular } \\
\text { formula }\end{array}$} & \multicolumn{2}{|c|}{$\begin{array}{c}U_{\text {eff }} \\
\text { (applied field) } \mathrm{cm}^{-1}\end{array}$} & \multicolumn{3}{|c|}{ Computed g-tensor } & $\begin{array}{l}\text { Dihedral } \\
\text { angle } \\
\text { (Dy-O-Zn- } \\
\text { O) }\left(^{\circ}\right)\end{array}$ \\
\hline & & Exp & Cal & $g_{x x}$ & gyy & $g_{z z}$ & \\
\hline 1 & 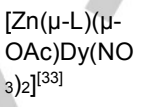 & - & 99.96 & 0.03 & 0.05 & 19.1 & 17.91 \\
\hline 2 & $\begin{array}{l}\mathrm{ZnBr}(\mathrm{Hsal})( \\
\mathrm{L}) \mathrm{Dy}\left(\mathrm{NO}_{3}\right)( \\
\left.\mathrm{CH}_{3} \mathrm{OH}\right)^{[1 \mathrm{e}]}\end{array}$ & 231,63 & 193.91 & 0.00 & 0.00 & 19.9 & 6.31 \\
\hline 3 & $\begin{array}{l}{[\mathrm{LZnDy}(\mathrm{OAc}} \\
\left.)_{3}\right]^{[34]}\end{array}$ & - & 121.25 & 0.03 & 0.04 & 19.4 & 22.45 \\
\hline 4 & $\begin{array}{l}{[\mathrm{Zn}(\mu-\mathrm{L})(\mu-} \\
9- \\
\mathrm{An}) \mathrm{Dy}\left(\mathrm{NO}_{3}\right) \\
2]^{[3 \mathrm{c}]}\end{array}$ & $\begin{array}{l}46.18 \\
(0.1 T)\end{array}$ & 82.65 & 0.02 & 0.04 & 18.8 & 15.37 \\
\hline 5 & $\begin{array}{l}\text { Complex } 3 \\
{\left[\mathrm{ZnDy}(\mathrm{L})_{2}(\mathrm{~N}\right.} \\
\left.\left.\mathrm{O}_{3}\right)_{2}(\mathrm{OAc})\right]\end{array}$ & $\begin{array}{c}83 \\
(0.35 \mathrm{~T})\end{array}$ & 91.07 & 0.022 & 0.04 & $18.8 \varepsilon$ & 26.67 \\
\hline
\end{tabular}

is pronounced as corroborated by a negligible $\left(0.02 \mu_{\mathrm{B}}\right)$ matrix element pertinent to this process. The transition moment matrix element corresponding to the TA-QTM process within the first excited multiplet is significant $\left(1.29 \mu_{\mathrm{B}}\right)$ to promote relaxation via this energy state. Additionally, the matrix element pertinent to the spin-phonon relaxation is also pronounced $1.55 \mu_{\mathrm{B}}$ to further provoke relaxation via the first excited energy level. Our wave function analysis affirms the ground state to be a mixture of two different $\left| \pm M_{J}\right\rangle$ states as: $0.43| \pm 15 / 2>+0.43| \pm 13 / 2>$. A suppressed QTM process within the ground energy multiplet is expected as a substantial negative axial crystal field parameter $\left(B_{2}^{0}\right)$ is found $(-1.23$ - see Table S13). This was supported by the extremely small non-axial crystal field parameter $\left(\sim 10^{-2}\right)$ which opens up relaxation probability via the first excited energy multiplets. The mechanism of relaxation analysis therefore supports a $U_{c a l}$ value of $98.35 \mathrm{~cm}^{-1}$. The $U_{c a l}$ value and the established relaxation mechanism are very close to that computed for complex 3 (nine coordinate), reported above, highlighting that the electronic properties are mainly influenced 
by polarization from the $\mathrm{Zn}$ (II) ion and the coordination number; nine vs. ten has little influence on the behavior. Moreover, this again reveals the value of incorporating a diamagnetic ion, in close proximity to a $\mathrm{Ln}^{\mathrm{III}}$ ion, as the barrier height is calculated to be bigger for [ $\mathrm{Zn} " \mathrm{Dy}$ "II $\left.\left(\mathrm{NO}_{3}\right)_{3} \mathrm{~L}\left(\mathrm{H}_{2} \mathrm{O}\right)\right]$ compared to the structurally similar complex, 1 which contains no such diamagnetic ion (see Table S3).

To understand the role of dihedral Dy-O-Zn-O angle, all the structures were carefully analyzed. It was found that the dihedral Dy-O-Zn-O angle plays a crucial role in pushing the excited state further away from the ground state, such that a smaller dihedral angle yields a large energy barrier and vice versa. When the dihedral angle deviation is small, the Dy(III) ion is forced into the same plane as the $\mathrm{Zn}(\mathrm{II})$ ion and the phenoxo oxygen atoms. This scenario leads to an enhanced electrostatic repulsion, due to the presence of the additional charge density on the bridging phenoxo ligand (due to the presence of the $\mathrm{Zn}$ (II) ion in the vicinity of $L n(I I I))$, compared to structures where the Dy(III) ion(s) deviate from planarity (See Table 4). The extent of distortion in the dihedral angle leads to distortion around the Dy(III) ion. Small deviations around the Dy(III) ion geometry stabilize a large

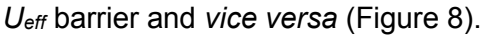

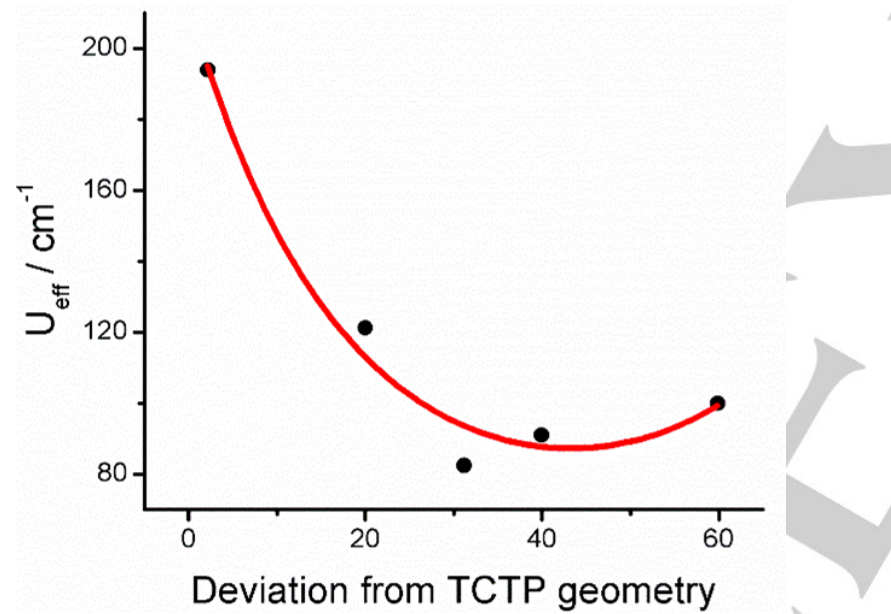

Figure 8. Plot of computed energy barrier for the complexes listed in Table 4 against the deviation from the ideal tricapped trigonal prism (TCTP) geometry calculated using continuous shape measurement software.

On the other hand, for the $\operatorname{Pr}(I I I)$ containing complexes ( 2 and 4) the computed electronic and magnetic properties show that complex 2 lacks SIM characteristics due to the absence of bistablity in the ground state energy levels (Table S14: all the energy levels are singlet in nature). Henceforth, no $g$ tensors have been computed for these singlet states. Similarly, the absence of SIM behavior in complex $\mathbf{4}$ was also observed due to the singlet nature of the ground and the first excited energy levels deterring us from calculating any $g$ tensor orientations and eventually preventing complex 4 to act as a SIM (see Table S15: detection of seven singlets and one pseudo-doublet). The experimental observations of the absence of SIM characteristics in complex $\mathbf{2}$ and $\mathbf{4}$ are well reproduced in our calculations.

DFT calculations, however, interestingly reveal that the coordinated oxygen atoms in $\mathbf{4}$ also have a higher negative charge compared to that of the coordinated oxygen atom in 2 (see Table S16-S17 and Figure S16-S17). The presence of the $\mathrm{Zn}$ (II) ion again results in a larger charge polarization on the oxygen atom, compared to the complex where the $\mathrm{Zn}(\mathrm{II})$ ion is absent which in turn induces a large electrostatic interaction on the lanthanide ions. This led to the comparatively larger energy for the first excited energy state in $\mathbf{4}$ compared to $\mathbf{2}$.

\section{Conclusions}

We have isolated two structurally analogous mononuclear $\left[\mathrm{Ln}(\mathrm{HL})_{2}\left(\mathrm{NO}_{3}\right)_{3}\right] \mathrm{Ln}=\mathrm{Dy}(1)$ or $\operatorname{Pr}(2)$ complexes which are characterized by single crystal $\mathrm{X}$-ray diffraction. To detail the effect of a diamagnetic $\mathrm{Zn}$ (II) ion in the vicinity of the $\mathrm{Ln}(\mathrm{III})$ coordination sphere we have isolated two structural similar heteronuclear complexes $\left[\mathrm{ZnDy}(\mathrm{L})_{2}\left(\mathrm{NO}_{3}\right)_{2}\left(\mathrm{CH}_{3} \mathrm{CO}_{2}\right)\right]$ (3) and $\left[\mathrm{Zn} 2 \mathrm{Pr}(\mathrm{L})_{2}\left(\mathrm{NO}_{3}\right)\left(\mathrm{CH}_{3} \mathrm{CO}_{2}\right)_{4}\right]$ (4), which contain the $\mathrm{Zn}(\mathrm{II})$ ion. Dc and ac magnetic susceptibility measurements were performed on $\mathbf{1}$ - $\mathbf{4}$ and it was revealed that complexes $\mathbf{1}$ and $\mathbf{3}$ display field induced single-molecule magnet behaviour. For both 1 and 3 more than one magnetization relaxation pathway is observed. The anisotropy barrier extracted from the ac data reveals a fivefold increase in the anisotropic barrier for 3 compared to 1 . This has been rationalized based on detailed $a b$ initio calculations. The reasons for such a significant increase were further corroborated via DFT calculations which predict that the additional charge density present in the bridging phenoxo ligand (due to the presence of the $\mathrm{Zn}$ (II) ion) in $\mathbf{3}$ pushes the first excited $m_{\lrcorner}$level away from the ground state $m_{\lrcorner}$level. While the absence of the $\mathbf{Z n}$ (II) ion in $\mathbf{1}$ and the distorted geometry around the Dy(III) ion result in a smaller ground state to first excited energy gap due to the smaller charges found on the coordinated O-atoms. A similar scenario is observed in complex 4 with the first excited state $m\lrcorner$ level being significantly higher than the ground state $m_{\lrcorner}$level compared to complex 2 where no $\mathrm{Zn}(\mathrm{II})$ ion is present. Further detailed theoretical investigations performed on literature reported $\mathrm{Zn}$-Dy complexes which are analogous to complex 3 indeed reveal that the dihedral angle between Dy-O$\mathrm{Zn}-\mathrm{O}$ holds the key to maximizing the electrostatic repulsion between the Dy(III) ion and the additional charge density found in phenoxo bridging ligands. The combination of excess charge density on the bridging ligand between the diamagnetic cation and paramagnetic lanthanide ion along with minimal dihedral distortion is the best combination to stabilize magnetic bistability in heteronuclear lanthanide complexes.

This study therefore reveals the unconventional method of utilizing a diamagnetic metal ion to improve the SMM behaviour in any lanthanide ion complex is a promising route for future SMM development.

\section{Experimental Section}

\section{Materials and methods}

All reactions were performed under aerobic condition unless otherwise specified. All the chemicals and solvents of analytical grade were purchased from Alfa Aesar and used without any further purification. The 
Schiff base ligand was synthesized as per the literature. ${ }^{[14 b, 35]}$ Infrared spectra were recorded for the solid samples using $\mathrm{KBr}$ pellets on a Perkin-Elmer FT-IR spectrometer in the 400 to $4000 \mathrm{~cm}^{-1}$ range. Magnetic susceptibility measurements were performed on a Quantum Design MPMS SQUID magnetometer as described previously. [11]

\section{X-ray crystallography}

Single crystal data were collected on a Bruker SMART Apex Duo diffractometer $\left(\mathrm{MoK}_{\alpha}, \lambda=0.71073 \AA\right)$. The selected crystals were mounted on a fibre loop using Paratone-N oil and placed in the cold flow produced with an Oxford Cryo-cooling device. Complete hemispheres of data were collected by using $\omega$ and $\varphi$-scans $(0.3 \AA, 30 \mathrm{~s}$ per frame). Integrated intensities were obtained with SAINT+ and they were corrected for absorption using SADABS. ${ }^{[36]}$ Structure solution and refinement was performed with the SHELX-package. The structures were solved by direct methods and completed by iterative cycles of $\Delta F$ syntheses and full-matrix least-squares refinement against $F^{2}$. It was not possible to solve the diffused electron density residual which was associated with solvent molecules for the complex 4 . This is treated with the SQUEEZE facility from PLATON resulted in smooth convergence of all the atoms during refinement. The loop corresponds to the residual electron density (created in PLATON) is appended in .cif file of the complex 4.

\section{Synthesis of 1}

The ligand $\mathrm{HL}(0.3 \mathrm{~g}, 1.3 \mathrm{mmol}))$ and $\mathrm{Dy}\left(\mathrm{NO}_{3}\right)_{3} \cdot 5 \mathrm{H}_{2} \mathrm{O}(0.2898 \mathrm{~g}, 0.6$ $\mathrm{mmol}$ ) were added to ethanol $(60 \mathrm{~mL})$ which resulted in an orange solution. This was then stirred for 7-8 hours. After completion of the reaction, the solution was filtered and kept for crystallization. Yellow/orange crystals were obtained upon slow evaporation of the solution at room temperature within 2-3 days. The obtained crystals, however, were found to be unsuitable for X-ray diffraction. The collected crystalline material was then recrystallized from methanol by allowing the solvent to evaporate slowly. These crystals were suitable for XRD. IR: (KBr pellet), $3424 \mathrm{~cm}^{-1}(\mathrm{~b},(\mathrm{NH})), 2942 \mathrm{~cm}^{-1}(\mathrm{~s},(\mathrm{Ar}-\mathrm{H})), 1630 \mathrm{~cm}^{-1}(\mathrm{~s},(\mathrm{C}=\mathrm{N}))$. Elemental analysis: Calc: C, $41.90 \%$; $\mathrm{H}, 3.30 \%$; N, $8.70 \%$. Found: C, $41.62 \% ; \mathrm{H}, 3.65 \%$; N, 8.77\%. Yield for 1 (\% based on $\left.\mathrm{Dy}^{3+}\right)=147 \mathrm{mg}$ $(27.7 \%)$

\section{Synthesis of 2}

The same procedure used to isolate complex 1 was followed, however $\operatorname{Pr}\left(\mathrm{NO}_{3}\right)_{3} \cdot 6 \mathrm{H}_{2} \mathrm{O}$ was used in place of $\mathrm{Dy}\left(\mathrm{NO}_{3}\right)_{3} \cdot 5 \mathrm{H}_{2} \mathrm{O}$. Suitable crystals for XRD were obtained from slow evaporation of the concentrated reaction mixture. IR: (KBr pellet), $3422 \mathrm{~cm}^{-1}(\mathrm{~b},(\mathrm{NH})), 2941 \mathrm{~cm}^{-1}(\mathrm{~s},(\mathrm{Ar}-\mathrm{H})), 1632 \mathrm{~cm}$ ${ }^{1}(\mathrm{~s},(\mathrm{C}=\mathrm{N}))$. Elemental analysis:Calc: $\mathrm{C}, 43.03 \% ; \mathrm{H}, 3.35 \%$; N, $8.96 \%$. Found: C, 42.92\%; H, 3.42\%; N, 8.69\%. Yield for 2 (\% based on $\mathrm{Pr}^{3+}$ ) $135 \mathrm{mg}(26.15 \%)$

\section{Synthesis of 3}

To a methanolic solution containing the Schiff base ligand $(0.3 \mathrm{~g}, 1.3$ $\mathrm{mmol}), \mathrm{NaOH}(0.0528 \mathrm{~g}, 1.3 \mathrm{mmol})$ was added followed by the addition of $\operatorname{Dy}\left(\mathrm{NO}_{3}\right)_{3} \cdot 5 \mathrm{H}_{2} \mathrm{O}(0.2898 \mathrm{~g}, 0.065 \mathrm{mmol})$. After $15-20$ minutes of stirring, $\mathrm{Zn}\left(\mathrm{CH}_{3} \mathrm{COO}\right)_{2} \cdot 2 \mathrm{H}_{2} \mathrm{O}(0.29 \mathrm{~g}, 1.3 \mathrm{mmol})$ was added to this solution. Upon addition of the zinc salt the solution changes from orange to yellow. The reaction mixture was then allowed to stir for 8 hours at room temperature. The solvent was then removed under reduced pressure and the product was extracted with DCM. The residue obtained after removal of the DCM was recrystallized from methanol. Suitable crystals for $\mathrm{x}$-ray diffraction were obtained within 2-3 days when left in the fridge at 4-5 ${ }^{\circ}$. IR: $(\mathrm{KBr}$ pellet), $2925 \mathrm{~cm}^{-1}(\mathrm{~s},(\mathrm{Ar}-\mathrm{H})), 1618 \mathrm{~cm}^{-1}(\mathrm{~s},(\mathrm{C}=\mathrm{N}))$. Elemental analysis: Calc: C, $41.70 \%$; $\mathrm{H}, 3.20 \%$; N, $6.50 \%$. Found: C, $41.62 \% ; \mathrm{H}, 3.15 \%$; N, $6.42 \%$. Yield for $3\left(\%\right.$ based on $\left.\mathrm{Dy}^{3+}\right)=160 \mathrm{mg}(28.04 \%)$

Synthesis of 4
Same procedure used to synthesis complex 3 was followed, however $\mathrm{Pr}\left(\mathrm{NO}_{3}\right)_{3} \cdot 6 \mathrm{H}_{2} \mathrm{O}$ was used in place of $\mathrm{Dy}\left(\mathrm{NO}_{3}\right)_{3} \cdot 5 \mathrm{H}_{2} \mathrm{O}$. IR: $(\mathrm{KBr}$ pellet $)$, $2922 \mathrm{~cm}^{-1}(\mathrm{~s},(\operatorname{Ar}-\mathrm{H})), 1615 \mathrm{~cm}^{-1}(\mathrm{~s},(\mathrm{C}=\mathrm{N}))$. Elemental analysis: Calc: C, $42.29 \%$; H, $3.55 \%$; N, $4.11 \%$. Found: C, $41.98 \%$;, $3.42 \%$; N, $4.10 \%$. Yield for 4 (\% based on $\left.\mathrm{Pr}^{3+}\right)=172 \mathrm{mg}(25.46 \%)$

\section{Acknowledgements}

MS wishes to thank the funding agencies DST (EMR/2015/000592), DST nanomission (SR/NM/NS-1119/2011) and IIT Bombay for financial support. GR, KSM and SKL acknowledge the support of an Australia-India AISRF grant. MS and GR thank Professor L. Chibotaru for access to the Molcas code. We thank Dr. B. Moubaraki for experimental assistance.

Keywords: Dysprosium • Praseodymium • Magnetism • clusters - Single-ion Magnets $\cdot A b$ initio calculations.

[1] a) R. J. Blagg, L. Ungur, F. Tuna, J. Speak, P. Comar, D. Collison, W. Wernsdorfer, E. J. L. McInnes, L. F. Chibotaru and R. E. P. Winpenny, Nat. Chem. 2013, 5, 673-678; b) N. F. Chilton, D. Collison, E. J. Mclnnes, R. E. Winpenny and A. Soncini, Nat Commun 2013, 4, 2551; c) N. F. Chilton, S. K. Langley, B. Moubaraki, A. Soncini, S. R. Batten and K. S. Murray, Chem. Sci. 2013, 4, 1719-1730; d) K. Liu, X. Zhang, X. Meng, W. Shi, P. Cheng and A. K. Powell, Chem. Soc. Rev. 2016, 45, 2423-2439; e) A. Watanabe, A. Yamashita, M. Nakano, T. Yamamura and T. Kajiwara, Chemistry 2011, 17, 7428-7432.

[2] N. Ishikawa, M. Sugita, T. Ishikawa, S.-Y. Koshihara and Y. Kaizu, J. Am. Chem. Soc. 2003, 125, 8694-8695.

[3] a) D. Aravena and E. Ruiz, Inorg. Chem. 2013, 52, 13770-13778 b) J. Luzon and R. Sessoli, Dalton Trans. 2012, 41, 1355613567; c) M. A. Palacios, S. Titos-Padilla, J. Ruiz, J. M. Herrera S. J. A. Pope, E. K. Brechin and E. Colacio, Inorg. Chem. 2014, 53, 1465-1474; d) J. Ruiz, A. J. Mota, A. Rodriguez-Dieguez, S. Titos, J. M. Herrera, E. Ruiz, E. Cremades, J. P. Costes and E. Colacio, Chem. Commun. 2012, 48, 7916-7918; e) D. N Woodruff, R. E. P. Winpenny and R. A. Layfield, Chem. Rev. (Washington, DC, U. S.) 2013, 113, 5110-5148; f) X. Yi, K Bernot, F. Pointillart, G. Poneti, G. Calvez, C. Daiguebonne, O. Guillou and R. Sessoli, Chem. - Eur. J. 2012, 18, 11379-11387, S11379/11371-S11379/11317; g) P. Zhang, L. Zhang, S.-Y. Lin and J. Tang, Inorg. Chem. 2013, 52, 6595-6602; h) K. Bader, M. Winkler and J. van Slageren, Chem. Commun. 2016, 52, 36233626; i) C. J. Wedge, G. A. Timco, E. T. Spielberg, R. E. George, F. Tuna, S. Rigby, E. J. L. Mclnnes, R. E. P. Winpenny, S. J. Blundell and A. Ardavan, Phys. Rev. Lett. 2012, 108, 107204/107201-107204/107205; j) E. Moreno Pineda, F. Chilton Nicholas, O. Sells Daniel, D. Collison, J. L. McInnes Eric, E. P. Winpenny Richard, R. Marx, M. Dorfel, P. Neugebauer, J. van Slageren and S.-D. Jiang, Nat Commun 2014, 5, 5243; k) R. E. P. Winpenny, Nat. Nanotechnol. 2013, 8, 159-160.

[4] C. Das, S. Vaidya, T. Gupta, J. M. Frost, M. Righi, E. K. Brechin M. Affronte, G. Rajaraman and M. Shanmugam, Chem. - Eur. J. 2015, 21, 15639-15650.

[5] a) S. K. Gupta, T. Rajeshkumar, G. Rajaraman and R. Murugavel, Chem. Sci. 2016, 7, 5181-5191; b) J. Liu, Y.-C. Chen, J.-L. Liu, V. Vieru, L. Ungur, J.-H. Jia, L. F. Chibotaru, Y. Lan, W Wernsdorfer, S. Gao, X.-M. Chen and M.-L. Tong, J. Am. Chem. Soc. 2016, 138, 5441-5450.

[6] Y.-S. Ding, N. F. Chilton, R. E. P. Winpenny and Y.-Z. Zheng Angew. Chem., Int. Ed. 2016, 55, 16071-16074.

[7] a) J. D. Rinehart, M. Fang, W. J. Evans and J. R. Long, J Am Chem Soc 2011, 133, 14236-14239; b) S. Demir, I.-R. Jeon, J. R. 
Long and T. D. Harris, Coord. Chem. Rev. 2015, 289-290, 149176; c) S. Demir, M. Nippe, M. I. Gonzalez and J. R. Long Chem. Sci. 2014, 5, 4701-4711; d) S. Demir, J. M. Zadrozny, M. Nippe and J. R. Long, J. Am. Chem. Soc. 2012, 134, 1854618549.

[8] a) N. Ahmed, C. Das, S. Vaidya, S. K. Langley, K. S. Murray and M. Shanmugam, Chem. - Eur. J. 2014, 20, 14235-14239; b) S. K Langley, D. P. Wielechowski, V. Vieru, N. F. Chilton, B. Moubaraki, B. F. Abrahams, L. F. Chibotaru and K. S. Murray, Angew. Chem., Int. Ed. 2013, 52, 12014-12019.

[9] J. D. Rinehart and J. R. Long, Chem. Sci. 2011, 2, 2078-2085.

[10] a) C. Das, A. Upadhyay, S. Vaidya, S. K. Singh, G. Rajaraman and M. Shanmugam, Chem. Commun. 2015, 51, 6137-6140; b) S. K. Singh, T. Gupta and G. Rajaraman, Inorg. Chem. 2014, 53, 10835-10845; c) S. K. Singh, T. Gupta, M. Shanmugam and G. Rajaraman, Chem. Commun. 2014, 50, 15513-15516.

[11] A. Upadhyay, S. K. Singh, C. Das, R. Mondol, S. K. Langley, K. S. Murray, G. Rajaraman and M. Shanmugam, Chem. Commun 2014, 50, 8838-8841.

[12] a) D. Anvir, O. Katzenelson, S. Keinan, M. Pinsky, Y. Pinto, Y. Salomon and H. Zabrodsky Hel-Or, CSM: Conceptual Aspects, England, 1997, p; b) H. Zabrodsky, S. Peleg and D. Avnir, J. Am. Chem. Soc. 1992, 114, 7843-7851.

[13] a) J.-P. Costes, F. Dahan and F. Nicodeme, Inorg. Chem. 2003 42, 6556-6563; b) W. Xie, M. J. Heeg and P. G. Wang, Inorg. Chem. 1999, 38, 2541-2543.

[14] a) A. Upadhyay, C. Das, M. Shanmugam, S. K. Langley, K. S. Murray and M. Shanmugam, Eur. J. Inorg. Chem. 2014, 2014 4320-4325; b) A. Upadhyay, S. Vaidya, V. S. Venkatasai, P. Jayapal, A. K. Srivastava, M. Shanmugam and M. Shanmugam, Polyhedron 2013, 66, 87-96.

[15] S. K. Langley, N. F. Chilton, L. Ungur, B. Moubaraki, L. F. Chibotaru and K. S. Murray, Inorg Chem 2012, 51, 11873-11881.

[16] a) J. P. Costes, S. Titos-Padilla, I. Oyarzabal, T. Gupta, C. Duhayon, G. Rajaraman and E. Colacio, Chem. - Eur. J. 2015, 21, 15785-15796; b) J. Long, J. Rouquette, J.-M. Thibaud, R. A S. Ferreira, L. D. Carlos, B. Donnadieu, V. Vieru, L. F. Chibotaru, L. Konczewicz, J. Haines, Y. Guari and J. Larionova, Angew. Chem., Int. Ed. 2015, 54, 2236-2240; c) I. Oyarzabal, J. Ruiz, E. Ruiz, D. Aravena, J. M. Seco and E. Colacio, Chem. Commun. 2015, 51, 12353-12356; d) I. Oyarzabal, J. Ruiz, J. M. Seco, M. Evangelisti, A. Camon, E. Ruiz, D. Aravena and E. Colacio Chem. - Eur. J. 2014, 20, 14262-14269; e) P.-Y. Shan, H.-F. Li, P. Chen, Y.-M. Tian, W.-B. Sun and P.-F. Yan, Z Anorg Allg Chem 2015, 641, 1119-1124; f) W.-B. Sun, P.-F. Yan, S.-D. Jiang, B.-W. Wang, Y.-Q. Zhang, H.-F. Li, P. Chen, Z.-M. Wang and S. Gao, Chem. Sci. 2016, 7, 684-691; g) P. L. Then, C Takehara, Y. Kataoka, M. Nakano, T. Yamamura and T. Kajiwara, Dalton Trans. 2015, 44, 18038-18048.

[17] a) P.-H. Lin, I. Korobkov, T. J. Burchell and M. Murugesu, Dalton Trans. 2012, 41, 13649-13655; b) P. Zhang, Y.-N. Guo and J. Tang, Coord. Chem. Rev. 2013, 257, 1728-1763.

[18] a) K. R. Meihaus and J. R. Long, J. Am. Chem. Soc. 2013, 135, 17952-17957; b) S.-D. Jiang, B.-W. Wang, H.-L. Sun, Z.-M. Wang and S. Gao, J. Am. Chem. Soc. 2011, 133, 4730-4733.

[19] a) M.-E. Boulon, G. Cucinotta, J. Luzon, C. Degl'Innocenti, M. Perfetti, K. Bernot, G. Calvez, A. Caneschi and R. Sessoli, Angew. Chem., Int. Ed. 2013, 52, 350-354; b) G. Cucinotta, M. Perfetti, J. Luzon, M. Etienne, P.-E. Car, A. Caneschi, G. Calvez, K. Bernot and R. Sessoli, Angew. Chem., Int. Ed. 2012, 51 1606-1610, S1606/1601-S1606/1611.

[20] a) S. M. J. Aubin, Z. Sun, H. J. Eppley, E. M. Rumberger, I. A. Guzei, K. Folting, P. K. Gantzel, A. L. Rheingold, G. Christou and D. N. Hendrickson, Inorg. Chem. 2001, 40, 2127-2146; b) C. Boskovic, M. Pink, J. C. Huffman, D. N. Hendrickson and G. Christou, J. Am. Chem. Soc. 2001, 123, 9914-9915; c) M. Soler, W. Wernsdorfer, Z. Sun, J. C. Huffman, D. N. Hendrickson and G. Christou, Chem. Commun. 2003, 2672-2673; d) M. Soler, W. Wernsdorfer, Z. Sun, D. Ruiz, J. C. Huffman, D. N. Hendrickson and G. Christou, Polyhedron 2003, 22, 1783-1788.
[21] a) F. Luan, T. Liu, P. Yan, X. Zou, Y. Li and G. Li, Inorg. Chem. 2015, 54, 3485-3490; b) F. Luan, P. Yan, J. Zhu, T. Liu, X. Zou and G. Li, Dalton Trans. 2015, 44, 4046-4053; c) L. Zhang, J. Jung, P. Zhang, M. Guo, L. Zhao, J. Tang and B. Le Guennic, Chem. - Eur. J. 2016, 22, 1392-1398.

[22] a) P.-E. Car, M. Perfetti, M. Mannini, A. Favre, A. Caneschi and R. Sessoli, Chem. Commun. 2011, 47, 3751-3753; b) M. Schienle, A. Kasten and P. H. Mueller, Phys Status Solidi B 1983, 119, 611-620.

[23] E. Lucaccini, M. Briganti, M. Perfetti, L. Vendier, J.-P. Costes, F Totti, R. Sessoli and L. Sorace, Chem. - Eur. J. 2016, 22, 55525562

[24] a) R. Marx, F. Moro, M. Doerfel, L. Ungur, M. Waters, S. D. Jiang, M. Orlita, J. Taylor, W. Frey, L. F. Chibotaru and J. van Slageren, Chem. Sci. 2014, 5, 3287-3293; b) Y. Rechkemmer, J. E. Fischer, R. Marx, M. Doerfel, P. Neugebauer, S. Horvath, M. Gysler, T. Brock-Nannestad, W. Frey, M. F. Reid and J. van Slageren, J. Am. Chem. Soc. 2015, 137, 13114-13120; c) K. S. Pedersen, J. Bendix and R. Clerac, Chem. Commun. 2014, 50, 4396-4415; d) K. S. Pedersen, J. Dreiser, H. Weihe, R. Sibille, H. V. Johannesen, M. A. Soerensen, B. E. Nielsen, M. Sigrist, H. Mutka, S. Rols, J. Bendix and S. Piligkos, Inorg. Chem. 2015, 54, 7600-7606; e) E. Lucaccini, L. Sorace, M. Perfetti, J.-P. Costes and R. Sessoli, Chem. Commun. 2014, 50, 1648-1651.

[25] a) F. Aquilante, L. De Vico, N. Ferré, G. Ghigo, P.-å. Malmqvist P. Neogrády, T. B. Pedersen, M. Pitoňák, M. Reiher, B. O. Roos, L. Serrano-Andrés, M. Urban, V. Veryazov and R. Lindh, J. Comput. Chem. 2010, 31, 224-247; b) G. Karlstroem, R. Lindh, P.-A. Malmqvist, B. O. Roos, U. Ryde, V. Veryazov, P.-O. Widmark, M. Cossi, B. Schimmelpfennig, P. Neogrady and L. Seijo, Comput Mater Sci 2003, 28, 222-239; c) V. Veryazov, P.O. Widmark, L. Serrano-Andres, R. Lindh and B. O. Roos, Int. J. Quantum Chem. 2004, 100, 626-635; d) J. A. Duncan, J. Am. Chem. Soc. 2009, 131, 2416.

[26] T. Gupta and G. Rajaraman, J. Chem. Sci. 2014, 126, 15691579.

[27] B. Swerts, L. F. Chibotaru, R. Lindh, L. Seijo, Z. Barandiaran, S. Clima, K. Pierloot and M. F. A. Hendrickx, J. Chem. Theory Comput. 2008, 4, 586-594.

[28] P. A. Malmqvist, B. O. Roos and B. Schimmelpfennig, Chem Phys Lett 2002, 357, 230-240.

[29] C. L. F. Ungur L in Vol. SINGLE_ANISO module in MOLCAS.

[30] K. Bernot, J. Luzon, L. Bogani, $\bar{M}$. Etienne, C. Sangregorio, M. Shanmugam, A. Caneschi, R. Sessoli and D. Gatteschi, J. Am. Chem. Soc. 2009, 131, 5573-5579.

[31] J.-L. Liu, Y.-C. Chen, Y.-Z. Zheng, W.-Q. Lin, L. Ungur, W. Wernsdorfer, L. F. Chibotaru and M.-L. Tong, Chem. Sci. 2013 4, 3310-3316.

[32] T. D. Pasatoiu, C. Tiseanu, A. M. Madalan, B. Jurca, C. Duhayon, J. P. Sutter and M. Andruh, Inorg. Chem. 2011, 50, 5879-5889.

[33] E. Colacio, J. Ruiz-Sanchez, F. J. White and E. K. Brechin, Inorg. Chem. 2011, 50, 7268-7273.

[34] S. Akine, F. Utsuno, T. Taniguchi and T. Nabeshima, Eur. J. Inorg. Chem. 2010, 3143-3152.

[35] A. Upadhyay, N. Komatireddy, A. Ghirri, F. Tuna, S. K. Langley, A. K. Srivastava, E. C. Sanudo, B. Moubaraki, K. S. Murray, E. J. McInnes, M. Affronte and M. Shanmugam, Dalton Trans 2014, 43, 259-266.

[36] SHELX-P C package 1998, Bruker Analytical X-ray Systems, Madison, $W I$. 